\title{
Broad Spectrum Antibacterial Ocotillol-Type Derivatives: Semi-Synthesis, Structure-Activity Relationship, and Membrane-Active Mode of Action
}

\author{
Xianming Zeng, ${ }^{a}$ Ziyi Zhang, ${ }^{a}$ Yunyun Zhou, ${ }^{\circ b}$ Shengyu Zhang ${ }^{a}$ and Zhiwen Zhou ${ }^{*, a}$ \\ ${ }^{a}$ Department of Pharmacy, Medical College, China Three Gorges University, 443002 Yichang, China \\ ${ }^{b}$ Department of Quality Control, China Resources Sanjiu Medical \& Pharmaceutical Co., Ltd., \\ 435000 Huangshi, China
}

\begin{abstract}
A series of 3-amino substituted ocotillol-type derivatives were designed and synthesized for the first time. The in vitro antibacterial activity tests showed that some of the new compounds exhibited excellent antibacterial activity. Compound 13d, which was the most active one, displayed particularly strong antibacterial activity against $S$. aureus, B. subtilis, MRSA (methicillin-resistant $S$. aureus) and $E$. coli with minimum inhibitory concentration (MIC) values of $1-4 \mu \mathrm{gL}^{-1}$. Further research also suggested that 13d showed low cytotoxicity to human normal cells HEK-293 and L02, strong synergistic effects with kanamycin or chloramphenicol and a broad antibacterial spectrum including against multidrug-resistant strains. This active molecule 13d also induced bacterial resistance more slowly than norfloxacin and colistin. Furthermore, the research results demonstrated that this type of compounds could disperse the established bacterial biofilms, thus suppressing or delaying the development of drug resistance. Mechanism studies have shown that compound 13d could damage the integrity of cell membranes, which in turn facilitated the antibacterial agents binding to deoxyribonucleic acid (DNA), leading to cell death. Therefore, these results indicated that the membrane active ocotillol-type derivatives are a promising class of antibacterial agents to fight against super bacteria and deserve further attention.
\end{abstract}

Keywords: ocotillol-type, bacterial resistance, antibacterial activity, mechanism

\section{Introduction}

The emergence of clinical drug-resistant strains poses a higher challenge to the treatment of infectious diseases. ${ }^{1}$ Multidrug-resistant (MDR) bacterial strains have arisen against all antibiotics in clinical use, associating with high mortality rates. The resistance of bacteria has seriously affected the efficacy of traditional antibiotics. Another major threat to human health is the formation of bacterial biofilms. Pathogens living in biotic biofilms often leads to prolonging therapeutic intervention and increasing bacterial resistance to antibiotics and the host immune system as a result of the diffusion barrier due to genetic mutation, extracellular matrix (EPS), slow metabolism, and so on. ${ }^{2}$ Compared with the planktonic cells, bacteria in a biofilm state are 10-1000-times more resistant to host immune responses and conventional antibiotic treatment. ${ }^{3}$ Hence, new antibacterial drugs with novel chemical scaffolds and targets are urgently required to combat infections due to drug-resistant strains.

*e-mail: zhiwen.zhou@ hotmail.com
Triterpenoids are the most representative group of natural products and many studies have reported the important role of triterpenoids in human health. Among which, ocotillol and related analogues (Figure 1, 1, 2, 3) have attracted particular attention for their significant biological activities such as anti-cancer, anti-oxidation, anti-myocardial ischemia and antibacterial effects, etc. ${ }^{4-7}$ In the previous work, ${ }^{7-10}$ we have designed and synthesized a novel series of derivatives based on ocotillol and found that this type of compounds exhibited good antibacterial and synergistic antibacterial activity against Gram-positive bacteria including multidrug-resistant (MDR) strains. The structure-activity relationships (SARs) of ocotillol-type antibacterial agents have been clearly summarized and elucidated, disclosing that the introduction of water-soluble groups, especially amino group, at C-3 position of steroid skeleton play an important role in antimicrobial activity. ${ }^{7-10}$ A plausible mechanism of action may be for the triterpenoid skeleton to provide a hydrophobic surface, while the E-ring and the amine (Figure 1) function as a polar head and tail to form a polar-apolar-polar amphiphile. This amphiphilic topology with appropriate physicochemical properties 
could play an important role by causing membrane damage or facilitating the uptake of the triterpenoids and antibiotics into cells. ${ }^{11}$ Additionally, the amine-enriched structure of cationic triterpenes (Figure 1, 4) has also been described in the literature to produce an antimicrobial action similar to that of detergents. This is most likely because the amino group formed a cationic configuration, showing a great advantage in avoiding bacterial resistance. ${ }^{12}$ Therefore, structural modification by converting the hydroxyl at C-3 to an amino group should be a promising pathway to obtain active antibacterial leads and overcome the resistance. Furthermore, these previously synthesized ocotillol-type derivatives also showed to have the ability to interact with the bases of double stranded deoxyribonucleic acid (DNA), which led to the cell death of bacteria. ${ }^{10}$ Thus, ocotillol-type compounds appear to be ideal antibacterial agents to supplement or to replace the existing antibiotic arsenal. However, the problems of poor water solubility and low amounts in plants limited the large-scale use of these ocotillol-type derivatives as clinical antibacterial agents.

In our previous effort for the discovery of new antibacterial agents, we have found that a 3-amino substituted ocotillol-type derivative (Figure 1, 11) exhibited mild to moderate antibacterial activity against a variety of drug-sensitive bacteria and drug-resistant bacteria. Moreover, this compound demonstrated improved water solubility due to the introduction of amino group, which was helpful for the improvement of bioavailability. These results suggested that compound $\mathbf{1 1}$ could be as lead for further research for broad-spectrum antimicrobial agents. However, although compound $\mathbf{1 1}$ has been recently showed to be active against both Gram-positive and Gram-negative strains, the antibacterial activity still need to be significantly enhanced in order to make the ocotillol-type derivatives novel potent. Therefore, in this study, we report our efforts for modification of compound $\mathbf{1 1}$ in order to make the derivatives with higher antibacterial activity and better water solubility. The structure-activity relationships and mechanism of action were also studied in depth.

\section{Experimental}

\section{General}

Most of the chemical reagents and solvents in the experiments were analytically pure and purified by the prescribed methods. Melting point was measured with a micro-melting point tester (XT-4) (Shanghai, China). ${ }^{1} \mathrm{H}$ and ${ }^{13} \mathrm{C}$ nuclear magnetic resonance (NMR) spectra were determined with Bruker AV-300 spectrometer (Berlin, Germany) using trimethylsilane (TMS) as an internal standard. The values of the chemical shifts are expressed in $\delta$ values (ppm) and the coupling constants $(J)$ in Hz. The results of high-resolution mass spectra (HRMS) were obtained by an Agilent QTOF 6520 (New York, United States). All fluorescence data were determined by an F-7000 spectrofluorimeter (Hitachi, Tokyo, Japan). The UV absorption spectrum was measured by a TU-2450 spectrophotometer (Puxi Analytic Instrument Ltd. of Beijing, China) at room temperature. Reagents and solvents such as methanol, dichloromethane, acetone, petroleum ether, ethyl acetate, acetic anhydride, hydroxylamine hydrochloride, sodium bicarbonate were purchased from Zechuan Chemical Reagent Company (Yichang, China). Cells and biochemical reagents were from Shanghai Institute of Medicine, Chinese Academy of Sciences (Shanghai, China).
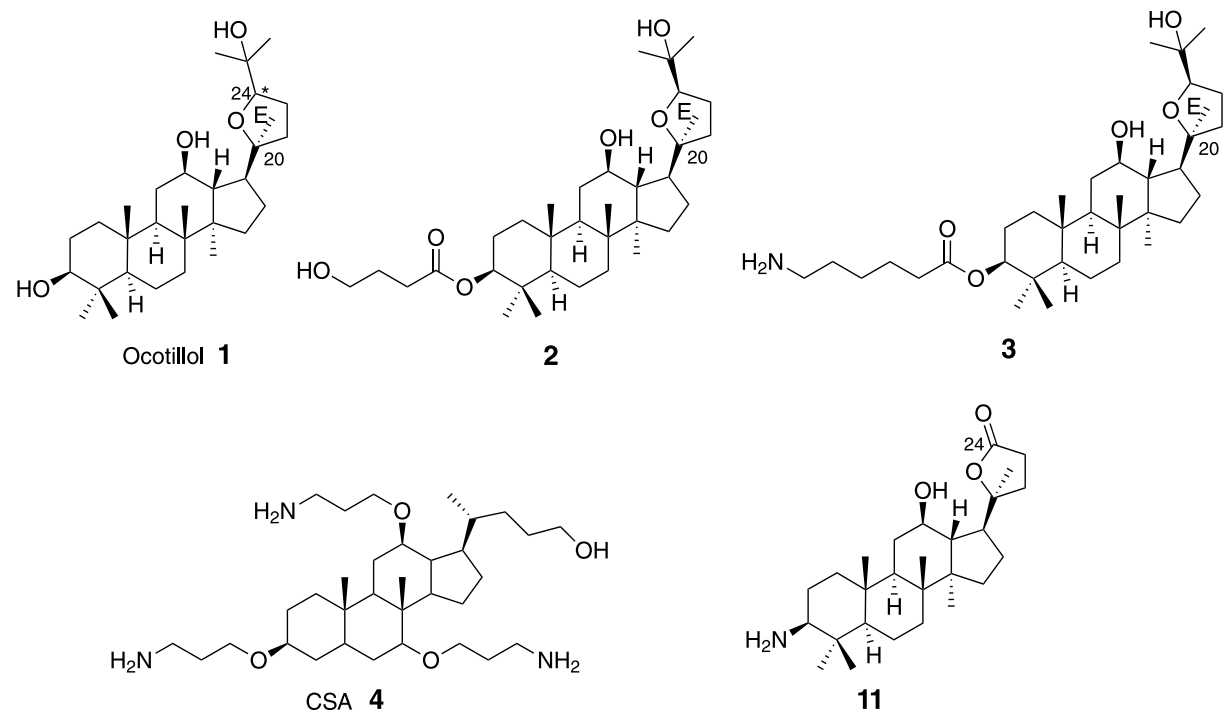

Figure 1. Structures of ocotillol and related analogues. 
General procedure for the synthesis of 20-(S)-protopanaxadiol (PPD)

PPD was prepared by alkaline hydrolysis with ginsenoside as raw material. ${ }^{13}$

\section{General procedure for the synthesis of lactone (8)}

The synthesis of compound $\mathbf{8}$ was carried out according to the method introduced previously, and PPD was used as the raw material. ${ }^{10}$

\section{General procedure for the synthesis of $\mathbf{9}$ and $\mathbf{1 0}$}

To a solution of $8(100 \mathrm{mg}, 0.24 \mathrm{mmol})$ in dry dichloromethane $(10 \mathrm{~mL})$ was added pyridinium chlorochromate $(63.8 \mathrm{mg}, 0.29 \mathrm{mmol})$. After the reaction solution was stirred at room temperature for $4 \mathrm{~h}$, the reaction mixture was then filtered. The organic solution was concentrated under vacuum, and the resulting mixture was then purified by silica gel column chromatography (6:1 petroleum ether-ethyl acetate) to give ketone $\mathbf{9}(82 \mathrm{mg}$, $80 \%)$.

To a solution of 9 (82 $\mathrm{mg}, 0.19 \mathrm{mmol})$ in anhydrous pyridine $(10 \mathrm{~mL})$ was added hydroxylamine hydrochloride (26 mg, $0.38 \mathrm{mmol})$. After the reaction solution was stirred at $70^{\circ} \mathrm{C}$ for $4 \mathrm{~h}$, the mixture was diluted with ethyl acetate. The organic layer was washed successively with $10 \%$ hydrochloric acid, water and brine. The washed organic layer was further dried with anhydrous sodium sulfate, then filtered and concentrated. The resulting mixture was then purified by silica gel column chromatography (4:1 petroleum ether-ethyl acetate) to give $\mathbf{1 0}$ (67 $\mathrm{mg}, 77 \%)$.

(20S,24)-Epoxy-24-carbonyl-12 $\beta$-hydroxyl dammarane3-one (9)

Mp 169-173 ${ }^{\circ} \mathrm{C} ;{ }^{1} \mathrm{H}$ NMR $\left(500 \mathrm{MHz}, \mathrm{CDCl}_{3}\right) \delta 3.53(\mathrm{td}$, $J 9.8,4.1 \mathrm{~Hz}, 1 \mathrm{H}, \mathrm{HOCH}), 2.46-2.52\left(\mathrm{~m}, 2 \mathrm{H}, \mathrm{COCH}_{2}\right), 2.41$ (dd, J 10.2, $6.5 \mathrm{~Hz}, 1 \mathrm{H}, \mathrm{COCH}), 2.24(\mathrm{td}, J 9.8,4.2 \mathrm{~Hz}, 1 \mathrm{H}$, $\mathrm{COCH}), 1.26\left(\mathrm{~s}, 3 \mathrm{H}, \mathrm{CH}_{3}\right), 1.21\left(\mathrm{~s}, 3 \mathrm{H}, \mathrm{CH}_{3}\right), 1.11(\mathrm{~s}, 3 \mathrm{H}$, $\mathrm{CH}_{3}$ ), 1.08 (s, 3H, $\mathrm{CH}_{3}$ ), 1.04 (s, 3H, $\mathrm{CH}_{3}$ ), 0.97 (s, 3H, $\mathrm{CH}_{3}$ ); ${ }^{13} \mathrm{C} \mathrm{NMR}\left(125 \mathrm{MHz}, \mathrm{CDCl}_{3}\right) \delta 217.4,176.6,85.2,70.5,70.1$, 55.4, 51.5, 49.4, 48.9, 47.5, 47.1, 39.8, 39.3, 36.7, 34.3, 33.9, 32.4, 31.5, 29.6, 28.6, 28.2, 27.4, 24.8, 20.9, 17.5, 16.0, 15.3; ESI-MS $m / z 431.3[\mathrm{M}+\mathrm{H}]^{+}$; HRMS (ESI) $m / z$, calcd. for $\mathrm{C}_{27} \mathrm{H}_{42} \mathrm{NaO}_{4}[\mathrm{M}+\mathrm{Na}]^{+}$: 453.2981, found: 453.2982.

$(20 S, 24)$-Epoxy-24-carbonyl-12 $\beta$-hydroxyl dammarane3-oxime (10)

$\mathrm{Mp} 161-165{ }^{\circ} \mathrm{C} ;{ }^{1} \mathrm{H}$ NMR $\left(300 \mathrm{MHz}, \mathrm{CDCl}_{3}\right) \delta 3.48$ (td, J 9.5, 3.8 Hz, 1H, HOCH), 2.41-2.48 (m, 2H, $\mathrm{COCH}_{2}$ ), $2.38(\mathrm{dd}, J 10.1,6.0 \mathrm{~Hz}, 1 \mathrm{H}, \mathrm{CNCH}), 2.30(\mathrm{td}, J 9.6,3.9 \mathrm{~Hz}$, 1H, CNCH), 1.29 (s, 3H, $\mathrm{CH}_{3}$ ), 1.25 (s, 3H, $\left.\mathrm{CH}_{3}\right), 1.13$ (s, $3 \mathrm{H}, \mathrm{CH}_{3}$ ), 1.05 (s, 3H, $\mathrm{CH}_{3}$ ), 1.01 (s, 3H, $\mathrm{CH}_{3}$ ), 0.99 (s, $\left.3 \mathrm{H}, \mathrm{CH}_{3}\right) ;{ }^{13} \mathrm{C} \mathrm{NMR}\left(75 \mathrm{MHz}, \mathrm{CDCl}_{3}\right) \delta 175.7,168.3,83.1$, 72.4, 69.8, 54.9, 51.6, 49.4, 49.0, 47.8, 47.3, 40.0, 39.6, $36.8,34.8,34.0,32.6,31.7,29.9,28.9,28.5,27.7,25.0$, 21.2, 18.5, 16.7, 15.8; ESI-MS m/z $446.3[\mathrm{M}+\mathrm{H}]^{+}$; HRMS (ESI) $m / z$, calcd. for $\mathrm{C}_{27} \mathrm{H}_{43} \mathrm{NNaO}_{4}[\mathrm{M}+\mathrm{Na}]^{+}: 468.3090$, found: 468.3097 .

\section{General procedure for the synthesis of $\mathbf{1 1}$}

To a solution of $\mathbf{1 0}(1.0 \mathrm{~g}, 2.24 \mathrm{mmol})$ in methanol $(30 \mathrm{~mL})$ was added sodium cyanoborohydride $(0.8 \mathrm{~g}$, $12 \mathrm{mmol})$ and ammonium acetate $(0.8 \mathrm{~g}, 10.8 \mathrm{mmol})$. The reaction solution was cooled to $0{ }^{\circ} \mathrm{C}$ with an ice bath and stirred under nitrogen atmosphere. Then, $15 \%$ aqueous titanium trichloride $(3.0 \mathrm{~mL})$ was added dropwise to the reaction solution in about $15 \mathrm{~min}$. After this, the reaction solution was stirred at room temperature for $16 \mathrm{~h}$. The reaction mixture adjusted to $\mathrm{pH} 7$ with sodium bicarbonate, was diluted with chloroform and the organic layer was washed successively with water and brine and concentrated to produce the mixture of $3 \alpha$ - and $3 \beta$-amine (720 mg).

To a solution of above mixture $(720 \mathrm{mg})$ in $\mathrm{CH}_{2} \mathrm{Cl}_{2}$ $(25 \mathrm{~mL})$ was added $\mathrm{Boc}_{2} \mathrm{O}(430 \mathrm{mg}, 1.9 \mathrm{mmol})$. The reaction solution was completed by stirring at room temperature for $6 \mathrm{~h}$, and then $\mathrm{CH}_{2} \mathrm{Cl}_{2}$ was added to the reaction solution for dilution. The organic layer was washed successively with water, brine and concentrated. The resulting mixture was then purified by silica gel column chromatography (8:1 petroleum ether-ethyl acetate) to give $(20 S, 24)$-epoxy24-carbonyl dammarane-3 $\beta$ - $N$-(tert-butoxycarbonyl)-12-ol (472 mg, 40\%).

To a solution of above purified intermediate $(472 \mathrm{mg}$, $0.88 \mathrm{mmol})$ in $\mathrm{CH}_{2} \mathrm{Cl}_{2}(15 \mathrm{~mL})$ was added trifluoroacetic acid $(0.7 \mathrm{~mL})$. The reaction solution was completed by stirring at room temperature for $4 \mathrm{~h}$, and then sodium bicarbonate was added to the reaction solution to adjust the $\mathrm{pH}$ to 7 . The reaction mixture was extracted with $\mathrm{CH}_{2} \mathrm{Cl}_{2}$, and the organic layer was washed successively with water, brine and concentrated. The resulting mixture was then purified by silica gel column chromatography (40:1 dichloromethane-methanol) to give 11 (20S,24)-epoxy24-carbonyl dammarane-3 $\beta$-amine-12-ol (292 mg, 76\%) as colorless liquid.

(20S,24)-Epoxy-24-carbonyl-12 $\beta$-hydroxyl dammarane3ß-amine (11)

$[\alpha]_{D}{ }^{25}+5.0^{\circ}\left(c 0.85, \mathrm{CHCl}_{3}\right) ; \mathrm{mp} 164-167{ }^{\circ} \mathrm{C} ;{ }^{1} \mathrm{H} \mathrm{NMR}$ $\left(500 \mathrm{MHz}, \mathrm{CDCl}_{3}\right) \delta 3.48(\mathrm{td}, J 9.3,4.6 \mathrm{~Hz}, 1 \mathrm{H}, \mathrm{HOCH})$, 
$2.82\left(\mathrm{dd}, J 8.9,4.8 \mathrm{~Hz}, 1 \mathrm{H}, \mathrm{NH}_{2} \mathrm{CH}\right), 2.11-2.20(\mathrm{~m}, 2 \mathrm{H}$, $\left.\mathrm{COCH}_{2}\right), 1.91-2.05\left(\mathrm{~m}, 2 \mathrm{H}, \mathrm{C}-\mathrm{CH}_{2}\right), 1.32\left(\mathrm{~s}, 3 \mathrm{H}, \mathrm{CH}_{3}\right), 1.08$ (s, 3H, $\left.\mathrm{CH}_{3}\right), 1.01\left(\mathrm{~s}, 3 \mathrm{H}, \mathrm{CH}_{3}\right), 0.93\left(\mathrm{~s}, 3 \mathrm{H}, \mathrm{CH}_{3}\right), 0.90$ (s, $\left.3 \mathrm{H}, \mathrm{CH}_{3}\right), 0.87$ (s, $\left.3 \mathrm{H}, \mathrm{CH}_{3}\right) ;{ }^{13} \mathrm{C}$ NMR $\left(125 \mathrm{MHz}, \mathrm{CDCl}_{3}\right)$ $\delta 176.4,83.5,78.5,57.1,55.8,55.7,54.2,42.5,40.4,39.7$, $38.8,38.5,37.6,35.1,34.3,32.0,29.6,28.0,27.6,27.1$, 26.5, 25.5, 25.0, 24.4, 18.3, 16.6, 16.0; ESI-MS $m / z 432.3$ $[\mathrm{M}+\mathrm{H}]^{+}$; HRMS (ESI) $\mathrm{m} / z$, calcd. for $\mathrm{C}_{27} \mathrm{H}_{45} \mathrm{NNaO}_{3}$ $[\mathrm{M}+\mathrm{Na}]^{+}:$454.3297, found: 454.3295 .

\section{General procedure for the synthesis of $11 a-11 i$ and $13 a-13 e$}

To a solution of $11(60 \mathrm{mg}, 0.13 \mathrm{mmol})$ in $\mathrm{CH}_{2} \mathrm{Cl}_{2}$ $(10 \mathrm{~mL})$ was added 1-ethyl-3-(3-dimethylaminopropyl) carbodiimide (EDCI, $52 \mathrm{mg}, 0.26 \mathrm{mmol}$ ), dimethylaminopyridine (DMAP) $(21 \mathrm{mg}, 0.15 \mathrm{mmol}$ ) and corresponding acids (or anhydrides). The reaction solution was completed by stirring at room temperature for 6-18 h, and then $\mathrm{CH}_{2} \mathrm{Cl}_{2}$ was added to the reaction solution for dilution. The organic layer was washed successively with $10 \% \mathrm{HCl}$, water and brine, then concentrated. The resulting mixture was purified by silica gel column chromatography (4:1-10:1 petroleum ether-ethyl acetate; 40:1-20:1 dichloromethane-methanol) to give the target compounds. Additionally, $11(80 \mathrm{mg}$, $0.19 \mathrm{mmol}$ ) was reacted with a series of Boc-amino acids (1.5 eq.) in dichloromethane (DCM) using the above method to give intermediates 12a-12e, and finally target compounds 13a-13e were obtained by deprotection using trifluoroacetic acid $(2 \mathrm{~mL})$. After completion, the reaction solution was then adjusted to $\mathrm{pH} 7$ with sodium bicarbonate, then extracted with dichloromethane and concentrated. The resulting residue was purified by silica gel column chromatography (30:1-10:1 dichloromethanemethanol) to give 13a-13e.

(20S,24)-Epoxy-24-carbonyl-3 $\beta$-acetylamino dammarane$12 \beta$-ol (11a)

White powder (46 mg, 75\%); mp 162-164 ${ }^{\circ} \mathrm{C} ;{ }^{1} \mathrm{H}$ NMR $\left(300 \mathrm{MHz}, \mathrm{CDCl}_{3}\right) \delta 3.41$ (td, $\left.J 8.8,4.2 \mathrm{~Hz}, 1 \mathrm{H}, \mathrm{HOCH}\right)$, 3.08 (dd, $J 9.2,5.5 \mathrm{~Hz}, 1 \mathrm{H}, \mathrm{NCH}), 2.15-2.23(\mathrm{~m}, 2 \mathrm{H}$, $\left.\mathrm{COCH}_{2}\right), 2.10$ (s, $\left.3 \mathrm{H}, \mathrm{COCH}_{3}\right), 1.89-2.03\left(\mathrm{~m}, 2 \mathrm{H}, \mathrm{C}-\mathrm{CH}_{2}\right)$, 1.28 (s, 3H, $\left.\mathrm{CH}_{3}\right), 1.12$ (s, 3H, $\left.\mathrm{CH}_{3}\right), 1.05$ (s, 3H, $\mathrm{CH}_{3}$ ), 0.99 (s, 3H, $\left.\mathrm{CH}_{3}\right), 0.95$ (s, 3H, $\left.\mathrm{CH}_{3}\right), 0.90$ (s, 3H, $\mathrm{CH}_{3}$ ); ${ }^{13} \mathrm{C}$ NMR $\left(75 \mathrm{MHz}, \mathrm{CDCl}_{3}\right) \delta 178.3,164.2,81.4,77.8$, 60.2, 56.7, 56.1, 54.5, 43.0, 41.8, 40.7, 39.5, 38.4, 38.1, $37.2,35.3,34.6,31.9,30.0,28.7,27.5,27.2,26.8,25.7$, 24.9, 24.7, 19.0, 16.9, 16.7; ESI-MS m/z 474.4 [M + H]+; HRMS (ESI) $\mathrm{m} / z$, calcd. for $\mathrm{C}_{29} \mathrm{H}_{48} \mathrm{NO}_{4}[\mathrm{M}+\mathrm{H}]^{+}: 474.3583$, found: 474.3584 .
(20S,24)-Epoxy-24-carbonyl-3 $\beta$-benzoylamino dammarane12ß-ol (11b)

White powder (53 mg, 77\%); mp 173-175 ${ }^{\circ} \mathrm{C} ;{ }^{1} \mathrm{H}$ NMR $\left(500 \mathrm{MHz}, \mathrm{CDCl}_{3}\right) \delta 8.05$ (t, J 7.8 Hz, 2H, Ph-H), 7.57 (t, $J 6.9 \mathrm{~Hz}, 1 \mathrm{H}, \mathrm{Ph}-\mathrm{H}$ ), 7.46 (t, J 7.2 Hz, 2H, Ph-H), 3.89 (dd, $J 8.4,3.9 \mathrm{~Hz}, 1 \mathrm{H}, \mathrm{HOCH}), 2.75(\mathrm{td}, J 6.2,4.3 \mathrm{~Hz}, 1 \mathrm{H}$, $\mathrm{NCH}), 2.22-2.29\left(\mathrm{~m}, 2 \mathrm{H}, \mathrm{COCH}_{2}\right), 1.30\left(\mathrm{~s}, 3 \mathrm{H}, \mathrm{CH}_{3}\right), 1.28$ (s, 3H, $\left.\mathrm{CH}_{3}\right), 1.19$ (s, 3H, $\left.\mathrm{CH}_{3}\right), 1.04$ (s, 3H, $\left.\mathrm{CH}_{3}\right), 0.98$ (s, $\left.3 \mathrm{H}, \mathrm{CH}_{3}\right), 0.89$ (s, $\left.3 \mathrm{H}, \mathrm{CH}_{3}\right) ;{ }^{13} \mathrm{C}$ NMR $\left(125 \mathrm{MHz}, \mathrm{CDCl}_{3}\right.$ ) $\delta$ 172.4, 166.4, 132.7, 131.5, 128.7, 126.6, 87.4, 82.6, 70.5, 70.2, 58.3, 53.5, 52.2, 51.7, 40.5, 39.8, 37.6, 36.6, 35.3, 33.6, 33.1, 32.7, 30.2, 28.5, 27.4, 25.2, 24.3, 19.6, 18.2, 16.5, 16.1, 15.8; ESI-MS $m / z 536.4[\mathrm{M}+\mathrm{H}]^{+}$; HRMS (ESI) $\mathrm{m} / z$, calcd. for $\mathrm{C}_{34} \mathrm{H}_{50} \mathrm{NO}_{4}[\mathrm{M}+\mathrm{H}]^{+}:$536.3740, found: 536.3745 .

(20S,24)-Epoxy-24-carbonyl-3 $\beta-N$-phenylpropenyl dammarane-12 $\beta$-ol (11c)

White powder ( $48 \mathrm{mg}, 66 \%)$; mp $173-175^{\circ} \mathrm{C} ;{ }^{1} \mathrm{H}$ NMR $\left(300 \mathrm{MHz}, \mathrm{CDCl}_{3}\right) \delta 7.63(\mathrm{~d}, J 13.2 \mathrm{~Hz}, 1 \mathrm{H}, \mathrm{C}=\mathrm{CH})$, 7.51-7.56 (m, 2H, Ph-H), 7.35-7.40 (m, 3H, Ph-H), 6.43 $(\mathrm{d}, J 13.2 \mathrm{~Hz}, 1 \mathrm{H}, \mathrm{C}=\mathrm{CH}), 3.89(\mathrm{dd}, J 9.6,4.3 \mathrm{~Hz}, 1 \mathrm{H}$, $\mathrm{HOCH}$ ), 2.77 (td, $J$ 9.2, $3.8 \mathrm{~Hz}, 1 \mathrm{H}, \mathrm{NCH}), 2.13-2.28$ (m, $\left.2 \mathrm{H}, \mathrm{COCH}_{2}\right), 1.27\left(\mathrm{~s}, 3 \mathrm{H}, \mathrm{CH}_{3}\right), 1.24\left(\mathrm{~s}, 3 \mathrm{H}, \mathrm{CH}_{3}\right), 1.13$ (s, $\left.3 \mathrm{H}, \mathrm{CH}_{3}\right), 1.05\left(\mathrm{~s}, 3 \mathrm{H}, \mathrm{CH}_{3}\right), 0.92\left(\mathrm{~s}, 3 \mathrm{H}, \mathrm{CH}_{3}\right), 0.88(\mathrm{~s}, 3 \mathrm{H}$, $\left.\mathrm{CH}_{3}\right) ;{ }^{13} \mathrm{C}$ NMR $\left(75 \mathrm{MHz}, \mathrm{CDCl}_{3}\right) \delta 173.6,166.6,145.3$, 134.5, 130.4, 129.3, 128.2, 118.8, 87.3, 80.4, 70.5, 70.0, $56.3,52.2,50.4,50.2,40.3,39.2,37.6,34.5,31.4,28.5$, 28.1, 27.5, 27.2, 25.5, 24.4, 23.6, 21.2, 18.2, 17.6, 16.4, 15.8, 15.5; ESI-MS $m / z 562.4[\mathrm{M}+\mathrm{H}]^{+}$; HRMS (ESI) $\mathrm{m} / z$, calcd. for $\mathrm{C}_{36} \mathrm{H}_{52} \mathrm{NO}_{4}[\mathrm{M}+\mathrm{H}]^{+}:$562.3896, found: 562.3897 .

(20S,24)-Epoxy-24-carbonyl-3 $3-N$-(3-picolinyl) dammarane$12 \beta$-ol (11d)

White powder (43 mg, 62\%); mp 181-183 ${ }^{\circ} \mathrm{C}$; ${ }^{1} \mathrm{H}$ NMR $\left(300 \mathrm{MHz}, \mathrm{CDCl}_{3}\right) \delta 9.23$ (s, 1H, Pyr-H), 8.75 (d, J $4.2 \mathrm{~Hz}$, 1H, Pyr-H), 8.26 (d, J 6.8 Hz, 1H, Pyr-H), 7.38 (t, J 6.5 Hz, $1 \mathrm{H}, \mathrm{Pyr}-\mathrm{H}), 3.84$ (t, J 7.1 Hz, 1H, HOCH), 2.68 (td, $J$ 6.8, $3.9 \mathrm{~Hz}, 1 \mathrm{H}, \mathrm{NCH}), 2.15-2.30\left(\mathrm{~m}, 2 \mathrm{H}, \mathrm{COCH}_{2}\right)$, $1.24\left(\mathrm{~s}, 3 \mathrm{H}, \mathrm{CH}_{3}\right), 1.22\left(\mathrm{~s}, 3 \mathrm{H}, \mathrm{CH}_{3}\right), 1.15\left(\mathrm{~s}, 3 \mathrm{H}, \mathrm{CH}_{3}\right)$, 1.05 (s, 3H, $\left.\mathrm{CH}_{3}\right), 0.94$ (s, 3H, $\mathrm{CH}_{3}$ ), 0.90 (s, 3H, $\mathrm{CH}_{3}$ ); ${ }^{13} \mathrm{C} \mathrm{NMR}\left(75 \mathrm{MHz}, \mathrm{CDCl}_{3}\right) \delta 172.5,165.3,153.1,151.3$, 137.4, 127.2, 123.6, 85.4, 82.1, 71.3, 68.2, 56.1, 52.4, 50.8, 49.2, 48.3, 40.2, 38.6, 38.3, 37.7, 35.5, 32.4, 31.5, 28.7, 28.4, 28.0, 26.5, 25.3, 24.4, 18.2, 16.8, 16.5, 15.5; ESI-MS $\mathrm{m} / \mathrm{z} 537.4$ [M + H] $]^{+}$; HRMS (ESI) $\mathrm{m} / z$, calcd. for $\mathrm{C}_{33} \mathrm{H}_{49} \mathrm{~N}_{2} \mathrm{O}_{4}[\mathrm{M}+\mathrm{H}]^{+}:$537.3692, found: 537.3697.

(20S,24)-Epoxy-24-carbonyl-3 $\beta-N$-(2-furan formyl) dammarane-12 $\beta$-ol (11e)

White powder ( $38 \mathrm{mg}, 56 \%)$; mp 167-169 ${ }^{\circ} \mathrm{C} ;{ }^{1} \mathrm{H}$ NMR $\left(300 \mathrm{MHz}, \mathrm{CDCl}_{3}\right) \delta 7.56$ (s, 1H, Fur-H), 7.15 (d, J $3.6 \mathrm{~Hz}$, 
1H, Fur-H), 6.45 (dd, J 3.6, 1.5 Hz, 1H, Fur-H), 3.91 (dd, $J$ 9.3, $5.1 \mathrm{~Hz}, 1 \mathrm{H}, \mathrm{HOCH}), 2.95(\mathrm{td}, J 9.6,3.8 \mathrm{~Hz}, 1 \mathrm{H}$, $\mathrm{NCH}), 2.12-2.22\left(\mathrm{~m}, 2 \mathrm{H}, \mathrm{COCH}_{2}\right), 1.25\left(\mathrm{~s}, 3 \mathrm{H}, \mathrm{CH}_{3}\right)$, 1.19 (s, 3H, $\left.\mathrm{CH}_{3}\right), 1.08$ (s, 3H, $\left.\mathrm{CH}_{3}\right), 0.95$ (s, 3H, $\mathrm{CH}_{3}$ ), 0.91 (s, $3 \mathrm{H}, \mathrm{CH}_{3}$ ), 0.89 (s, $\left.3 \mathrm{H}, \mathrm{CH}_{3}\right) ;{ }^{13} \mathrm{C}$ NMR $(75 \mathrm{MHz}$, $\left.\mathrm{CDCl}_{3}\right) \delta 167.4,158.6,146.5,145.7,117.3,111.6,87.5$, 81.4, 70.5, 70.1, 56.4, 52.6, 50.3, 49.4, 40.2, 38.6, 38.1, $37.5,35.0,32.7,32.0,31.6,29.3,28.5,28.1,25.5,24.6$, 18.7, 18.3, 16.9, 16.5, 15.9; ESI-MS $\mathrm{m} / z$ $526.4[\mathrm{M}+\mathrm{H}]^{+}$; HRMS (ESI) $m / z$, calcd. for $\mathrm{C}_{32} \mathrm{H}_{48} \mathrm{NO}_{5}[\mathrm{M}+\mathrm{H}]^{+}: 526.3532$, found: 526.3532 .

(20S,24)-Epoxy-24-carbonyl-3 $\beta-N$-(3-carboxy propionyl) dammarane-12 $\beta$-ol (11f)

White powder $(36 \mathrm{mg}, 52 \%) ;[\alpha]_{D}{ }^{25}+7.1^{\circ}$ (c 0.49 , $\mathrm{CHCl}_{3}$ ); mp 183-185 ${ }^{\circ} \mathrm{C} ;{ }^{1} \mathrm{H}$ NMR (300 MHz, $\mathrm{CDCl}_{3}$ ) $\delta 3.81(\mathrm{t}, J 8.8,5.2 \mathrm{~Hz}, 1 \mathrm{H}, \mathrm{HOCH}), 2.96(\mathrm{dd}, J 9.2,5.3 \mathrm{~Hz}$, $1 \mathrm{H}, \mathrm{NCH}), 2.61-2.65\left(\mathrm{~m}, 4 \mathrm{H}, \mathrm{COCH}_{2} \mathrm{CH}_{2} \mathrm{CO}\right), 2.13-2.20$ $\left(\mathrm{m}, 2 \mathrm{H}, \mathrm{COCH}_{2}\right), 1.27\left(\mathrm{~s}, 3 \mathrm{H}, \mathrm{CH}_{3}\right), 1.24\left(\mathrm{~s}, 3 \mathrm{H}, \mathrm{CH}_{3}\right), 1.02$ (s, $\left.3 \mathrm{H}, \mathrm{CH}_{3}\right), 1.00$ (s, 3H, $\left.\mathrm{CH}_{3}\right), 0.97$ (s, 3H, $\left.\mathrm{CH}_{3}\right), 0.89$ (s, $3 \mathrm{H}, \mathrm{CH}_{3}$ ); ${ }^{13} \mathrm{C}$ NMR $\left(75 \mathrm{MHz}, \mathrm{CDCl}_{3}\right) \delta 177.3,172.5$, 166.4, 85.4, 81.3, 71.2, 70.5, 56.3, 52.2, 50.6, 49.3, 48.2, $40.2,39.5,38.6,37.5,35.8,33.1,31.4,31.0,29.6,28.7$, 28.1, 27.6, 26.6, 25.3, 24.2, 18.3, 16.7, 16.2, 15.8; ESI-MS $\mathrm{m} / z 532.4[\mathrm{M}+\mathrm{H}]^{+}$; HRMS (ESI) $\mathrm{m} / z$, calcd. for $\mathrm{C}_{31} \mathrm{H}_{50} \mathrm{NO}_{6}$ $[\mathrm{M}+\mathrm{H}]^{+}: 532.3638$, found: 532.3633 .

(20S,24)-Epoxy-24-carbonyl-3 $\beta-N$-(4-carboxybutyryl) dammarane-12 $\beta$-ol (11g)

White powder $(38 \mathrm{mg}, 54 \%) ;[\alpha]_{D}^{25}+7.8^{\circ}(c 0.60$, $\left.\mathrm{CHCl}_{3}\right)$; mp 190-191 ${ }^{\circ} \mathrm{C} ;{ }^{1} \mathrm{H}$ NMR $\left(\mathrm{CDCl}_{3}, 300 \mathrm{MHz}\right)$ $\delta 3.81$ (t, $J 8.2 \mathrm{~Hz}, 1 \mathrm{H}, \mathrm{HOCH}), 2.89$ (td, $J 9.2,3.8 \mathrm{~Hz}$, $1 \mathrm{H}, \mathrm{NCH}), 2.29-2.39\left(\mathrm{~m}, 4 \mathrm{H}, \mathrm{COCH}_{2} \mathrm{CH}_{2} \mathrm{CH}_{2} \mathrm{CO}\right)$, 2.15-2.22 (m, 2H, $\left.\mathrm{COCH}_{2}\right), 1.25$ (s, 3H, $\left.\mathrm{CH}_{3}\right), 1.12$ (s, $\left.3 \mathrm{H}, \mathrm{CH}_{3}\right), 1.07$ (s, 3H, $\left.\mathrm{CH}_{3}\right), 1.01$ (s, 3H, $\left.\mathrm{CH}_{3}\right), 0.91$ (s, $\left.3 \mathrm{H}, \mathrm{CH}_{3}\right), 0.88\left(\mathrm{~s}, 3 \mathrm{H}, \mathrm{CH}_{3}\right) ;{ }^{13} \mathrm{C} \mathrm{NMR}\left(75 \mathrm{MHz}, \mathrm{CDCl}_{3}\right)$ $\delta$ 176.2, 171.5, 164.8, 85.1, 81.1, 70.5, 68.2, 55.8, 52.1, 50.4, 49.5, 46.6, 39.2, 38.9, 37.8, 36.9, 35.0, 34.2, 32.7, $31.5,31.2,30.3,29.5,28.7,28.1,27.6,26.5,24.7,17.9$, 16.8, 16.4, 15.8; ESI-MS $m / z$ 546.4 [M + H]+; HRMS (ESI) $\mathrm{m} / z$, calcd. for $\mathrm{C}_{32} \mathrm{H}_{52} \mathrm{NO}_{6}[\mathrm{M}+\mathrm{H}]^{+}:$546.3795, found: 546.3792 .

(20S,24)-Epoxy-24-carbonyl-3 $\beta-N$-(2E-ene butyryl) dammarane-12 $\beta$-ol (11h)

White powder (30 mg, 43\%); mp 201-205 ${ }^{\circ} \mathrm{C} ;{ }^{1} \mathrm{H}$ NMR (300 MHz, $\left.\mathrm{CDCl}_{3}\right) \delta 6.38(\mathrm{~d}, J 6.5 \mathrm{~Hz}, 1 \mathrm{H}, \mathrm{C}=\mathrm{CH}), 5.62$ $(\mathrm{d}, J 6.5 \mathrm{~Hz}, 1 \mathrm{H}, \mathrm{C}=\mathrm{CH}), 3.65$ (td, $J 8.2,3.6 \mathrm{~Hz}, 1 \mathrm{H}$, $\mathrm{HOCH}$ ), 3.12 (dd, $J 8.5,3.2 \mathrm{~Hz}, 1 \mathrm{H}, \mathrm{NCH}), 2.12-2.30$ (m, $\left.2 \mathrm{H}, \mathrm{COCH}_{2}\right), 1.26$ (s, 3H, $\left.\mathrm{CH}_{3}\right), 1.19$ (s, 3H, $\left.\mathrm{CH}_{3}\right), 1.13$ (s, 3H, $\mathrm{CH}_{3}$ ), 0.99 (s, 3H, $\mathrm{CH}_{3}$ ), 0.90 (s, 3H, $\left.\mathrm{CH}_{3}\right), 0.87$ (s, $\left.3 \mathrm{H}, \mathrm{CH}_{3}\right) ;{ }^{13} \mathrm{C} \mathrm{NMR}\left(\mathrm{CDCl}_{3}, 75 \mathrm{MHz}\right) \delta 172.2,168.1$, 165.2, 123.1, 117.5, 87.3, 87.0, 70.2, 69.9, 55.2, 52.0, 48.9, 47.1, 39.3, 38.7, 37.6, 36.6, 35.5, 34.7, 32.5, 31.7, 30.6, 29.8, 28.6, 27.8, 26.6, 24.5, 18.1, 16.9, 16.6, 15.9; ESI-MS $\mathrm{m} / z 530.3[\mathrm{M}+\mathrm{H}]^{+} ; \mathrm{HRMS}$ (ESI) $\mathrm{m} / z$, calcd. for $\mathrm{C}_{31} \mathrm{H}_{48} \mathrm{NO}_{6}$ $[\mathrm{M}+\mathrm{H}]^{+}:$530.3482, found: 530.3489 .

(20S,24)-Epoxy-24-carbonyl-3 $\beta-N$-(2-carboxybenzoyl) dammarane-12 $\beta$-ol (11i)

White powder (33 mg, 43\%); mp 208-210 ${ }^{\circ} \mathrm{C}$; ${ }^{1} \mathrm{H}$ NMR $\left(\mathrm{CDCl}_{3}, 300 \mathrm{MHz}\right) \delta 7.85(\mathrm{t}, J 6.1 \mathrm{~Hz}, 1 \mathrm{H}, \mathrm{Ph}-\mathrm{H}), 7.74(\mathrm{t}$, $J 5.8 \mathrm{~Hz}, 1 \mathrm{H}, \mathrm{Ph}-\mathrm{H}), 7.52(\mathrm{t}, J 5.9 \mathrm{~Hz}, 2 \mathrm{H}, \mathrm{Ph}-\mathrm{H}), 3.92(\mathrm{t}$, $J 8.5 \mathrm{~Hz}, 1 \mathrm{H}, \mathrm{HOC} H), 3.05(\mathrm{dd}, J 9.8,5.6 \mathrm{~Hz}, 1 \mathrm{H}, \mathrm{NCH})$, $2.21\left(\mathrm{t}, J 7.3 \mathrm{~Hz}, 2 \mathrm{H}, \mathrm{COCH}_{2}\right), 1.27\left(\mathrm{~s}, 3 \mathrm{H}, \mathrm{CH}_{3}\right), 1.25$ (s, $\left.3 \mathrm{H}, \mathrm{CH}_{3}\right), 1.10$ (s, 3H, $\left.\mathrm{CH}_{3}\right), 0.99$ (s, 3H, $\left.\mathrm{CH}_{3}\right), 0.90$ (s, $\left.3 \mathrm{H}, \mathrm{CH}_{3}\right), 0.88$ (s, $\left.3 \mathrm{H}, \mathrm{CH}_{3}\right) ;{ }^{13} \mathrm{C}$ NMR $\left(75 \mathrm{MHz}, \mathrm{CDCl}_{3}\right.$ ) $\delta$ 175.1, 169.4, 167.2, 132.5, 131.7, 130.3, 130.1, 128.9, 128.1, 86.7, 82.1, 70.2, 69.8, 55.8, 51.7, 49.7, 48.2, 47.8, $39.3,38.2,37.6,36.6,34.2,31.9,31.3,30.4,28.3,28.0$, 27.7, 26.2, 25.2, 23.3, 16.8, 16.6, 15.6; ESI-MS $\mathrm{m} / \mathrm{z} 580.4$ $[\mathrm{M}+\mathrm{H}]^{+}$; HRMS (ESI) $m / z$, calcd. for $\mathrm{C}_{35} \mathrm{H}_{50} \mathrm{NO}_{6}[\mathrm{M}+\mathrm{H}]^{+}$: 580.3638, found: 580.3631 .

(20S,24)-Epoxy-3 $\beta-N$-(2-amino acetyl)-24-carbonyl dammarane-12 $\beta$-ol (13a)

White powder $(41 \mathrm{mg}, 45 \%) ;[\alpha]_{D}{ }^{25}+3.8^{\circ}$ (c 0.82 , $\mathrm{CH}_{3} \mathrm{OH}$ ); mp 212-215 ${ }^{\circ} \mathrm{C} ;{ }^{1} \mathrm{H}$ NMR (300 MHz, $\mathrm{CDCl}_{3}$ ) $\delta 5.56(\mathrm{~s}, 1 \mathrm{H}, \mathrm{OH}), 5.31\left(\mathrm{~s}, 2 \mathrm{H}, \mathrm{NCH}_{2} \mathrm{CO}\right), 3.85(\mathrm{dd}, J 7.9$, $5.2 \mathrm{~Hz}, 1 \mathrm{H}, \mathrm{HOCH}), 2.95(\mathrm{td}, J 9.5,3.8 \mathrm{~Hz}, 1 \mathrm{H}, \mathrm{NCH})$, 2.16-2.28 (m, $\left.2 \mathrm{H}, \mathrm{COCH}_{2}\right), 1.26\left(\mathrm{~s}, 3 \mathrm{H}, \mathrm{CH}_{3}\right), 1.23$ (s, $\left.3 \mathrm{H}, \mathrm{CH}_{3}\right), 1.06$ (s, 3H, $\left.\mathrm{CH}_{3}\right), 0.99$ (s, 3H, $\left.\mathrm{CH}_{3}\right), 0.91$ (s, $\left.3 \mathrm{H}, \mathrm{CH}_{3}\right), 0.88$ (s, $\left.3 \mathrm{H}, \mathrm{CH}_{3}\right) ;{ }^{13} \mathrm{C} \mathrm{NMR}\left(75 \mathrm{MHz}, \mathrm{CDCl}_{3}\right.$ ) $\delta$ 172.8, 165.6, 82.6, 82.4, 70.8, 70.1, 59.6, 59.3, 55.5, 51.6, 50.3, 49.3, 47.5, 46.8, 46.2, 39.5, 38.4, 37.8, 34.6, 32.4, 31.2, 27.9, 27.4, 26.3, 24.6, 23.7, 18.2, 16.5, 15.6; ESI-MS $m / z 489.4$ [M + H] ; HRMS (ESI) $m / z$, calcd. for $\mathrm{C}_{29} \mathrm{H}_{48} \mathrm{~N}_{2} \mathrm{NaO}_{4}[\mathrm{M}+\mathrm{Na}]^{+}:$511.3512, found: 511.3516 .

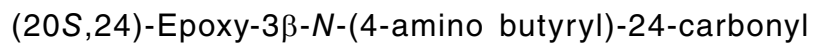
dammarane-12 $\beta$-ol (13b)

White powder $(40 \mathrm{mg}, 41 \%) ;[\alpha]_{D}{ }^{25}+3.2^{\circ}(c \quad 0.80$, $\left.\mathrm{CH}_{3} \mathrm{OH}\right) ; \mathrm{mp} 215-218{ }^{\circ} \mathrm{C} ;{ }^{1} \mathrm{H}$ NMR $\left(300 \mathrm{MHz}, \mathrm{CDCl}_{3}\right.$ ) $\delta 4.49$ (t, $J 7.9 \mathrm{~Hz}, 1 \mathrm{H}, \mathrm{HOCH}$ ), 3.07 (td, $J 10.4,4.5 \mathrm{~Hz}$, $1 \mathrm{H}, \mathrm{NCH}), 2.86\left(\mathrm{td}, J 7.6,3.1 \mathrm{~Hz}, 2 \mathrm{H}, \mathrm{NCH}_{2}\right), 2.34-2.45$ (m, 4H, $\mathrm{NCOCH}_{2}, \mathrm{CONH}_{2}$ ), $1.24\left(\mathrm{~s}, 3 \mathrm{H}, \mathrm{CH}_{3}\right), 1.14$ (s, $\left.3 \mathrm{H}, \mathrm{CH}_{3}\right), 1.12\left(\mathrm{~s}, 3 \mathrm{H}, \mathrm{CH}_{3}\right), 0.93\left(\mathrm{~s}, 3 \mathrm{H}, \mathrm{CH}_{3}\right), 0.90$ (s, $\left.3 \mathrm{H}, \mathrm{CH}_{3}\right), 0.89$ (s, $\left.3 \mathrm{H}, \mathrm{CH}_{3}\right) ;{ }^{13} \mathrm{C}$ NMR $\left(75 \mathrm{MHz}, \mathrm{CDCl}_{3}\right.$ ) $\delta$ 176.3, 172.6, 85.2, 81.0, 71.2, 69.8, 56.5, 52.1, 50.6, 49.4, 47.8, 44.0, 39.6, 38.7, 37.7, 36.9, 35.4, 35.0, 34.7, 32.6, 31.1, 28.7, 28.0, 27.7, 27.3, 26.4, 24.9, 23.3, 18.4, 16.5, 15.7; ESI-MS $m / z$ 517.4 [M + H] . 
(20S,24)-Epoxy-3 $\beta-N$-(6-aminocaproyl)-24-carbonyl dammarane-12 $\beta$-ol (13c)

White powder (36 $\mathrm{mg}, 35 \%) ;[\alpha]_{D}{ }^{25}+2.5^{\circ}(c 0.62$, $\left.\mathrm{CH}_{3} \mathrm{OH}\right) ; \operatorname{mp} 225-227{ }^{\circ} \mathrm{C} ;{ }^{1} \mathrm{H}$ NMR $\left(300 \mathrm{MHz}, \mathrm{CDCl}_{3}\right.$ ) $\delta 5.30(\mathrm{~s}, 1 \mathrm{H}, \mathrm{OH}), 4.51(\mathrm{t}, J 7.2 \mathrm{~Hz}, 1 \mathrm{H}, \mathrm{HOCH}), 3.08(\mathrm{td}$, $J$ 5.3, $\left.2.7 \mathrm{~Hz}, 2 \mathrm{H}, \mathrm{NCH}_{2}\right), 2.89(\mathrm{td}, J 8.6,3.9 \mathrm{~Hz}, 1 \mathrm{H}, \mathrm{NCH})$, 2.23-2.30 (m, 2H, $\left.\mathrm{NCOCH}_{2}\right), 2.17-2.20\left(\mathrm{~m}, 2 \mathrm{H}, \mathrm{COCH}_{2}\right)$, $1.26\left(\mathrm{~s}, 3 \mathrm{H}, \mathrm{CH}_{3}\right), 1.12\left(\mathrm{~s}, 3 \mathrm{H}, \mathrm{CH}_{3}\right), 1.08\left(\mathrm{~s}, 3 \mathrm{H}, \mathrm{CH}_{3}\right), 1.00$ (s, 3H, $\left.\mathrm{CH}_{3}\right), 0.91\left(\mathrm{~s}, 3 \mathrm{H}, \mathrm{CH}_{3}\right), 0.87\left(\mathrm{~s}, 3 \mathrm{H}, \mathrm{CH}_{3}\right) ;{ }^{13} \mathrm{C} \mathrm{NMR}$ $\left(75 \mathrm{MHz}, \mathrm{CDCl}_{3}\right) \delta 176.4,168.3,87.4,81.1,70.8,70.3,56.2$, 52.4, 50.5, 49.7, 48.1, 44.3, 39.7, 38.9, 37.8, 37.1, 36.2, 35.6, $35.2,34.8,32.8,31.3,28.5,28.2,27.8,26.9,26.2,25.1,23.5$, 18.7, 17.6, 16.8, 15.9; ESI-MS m/z 545.4 [M + H] $]^{+}$.

(20S,24)-Epoxy-3 $\beta-N$-(8-amino nonyl)-24-carbonyl dammarane-12 $\beta$-ol (13d)

White powder $(34 \mathrm{mg}, 32 \%) ;[\alpha]_{D}{ }^{25}+2.1^{\circ}$ (c 0.51 , $\left.\mathrm{CH}_{3} \mathrm{OH}\right) ; \operatorname{mp} 223-227{ }^{\circ} \mathrm{C} ;{ }^{1} \mathrm{H}$ NMR $\left(300 \mathrm{MHz}, \mathrm{CDCl}_{3}\right.$ ) $\delta 5.60(\mathrm{~s}, 1 \mathrm{H}, \mathrm{OH}), 3.85(\mathrm{t}, J 8.3 \mathrm{~Hz}, 1 \mathrm{H}, \mathrm{HOCH}), 3.06-3.18$ $\left(\mathrm{m}, 2 \mathrm{H}, \mathrm{NCH}_{2}\right), 2.85(\mathrm{td}, J 9.2,4.5 \mathrm{~Hz}, 1 \mathrm{H}, \mathrm{NCH})$, 2.18-2.28 (m, 2H, $\left.\mathrm{NCOCH}_{2}\right), 2.03-2.11\left(\mathrm{~m}, 2 \mathrm{H}, \mathrm{COCH}_{2}\right)$, 1.29 (s, 3H, $\left.\mathrm{CH}_{3}\right), 1.15$ (s, 3H, $\left.\mathrm{CH}_{3}\right), 1.06$ (s, 3H, $\left.\mathrm{CH}_{3}\right)$, 1.01 (s, 3H, $\left.\mathrm{CH}_{3}\right), 0.92$ (s, 3H, $\left.\mathrm{CH}_{3}\right), 0.87$ (s, 3H, $\left.\mathrm{CH}_{3}\right)$; ${ }^{13} \mathrm{C} \mathrm{NMR}\left(75 \mathrm{MHz}, \mathrm{CDCl}_{3}\right) \delta 171.4,167.4,86.4,85.3,70.9$, 70.0, 55.3, 51.9, 49.7, 49.4, 47.8, 47.2, 39.7, 39.5, 36.7, $34.1,33.9,32.5,31.6,31.1,29.6,28.5,27.8,27.4,26.6$, 26.1, 24.9, 20.8, 19.5, 18.7, 17.9, 17.2, 16.8, 16.1, 15.5; ESI-MS $m / z 573.5[\mathrm{M}+\mathrm{H}]^{+}$; HRMS (ESI) $m / z$, calcd. for $\mathrm{C}_{35} \mathrm{H}_{61} \mathrm{~N}_{2} \mathrm{O}_{4}[\mathrm{M}+\mathrm{H}]^{+}:$573.4631, found: 573.4635 .

(20S,24)-Epoxy-3 $\beta-N$-(10-Aminodecanoyl)-24-carbonyl dammarane-12 $\beta$-ol (13e)

White powder (31 mg, 28\%); $\mathrm{mp} 228-230{ }^{\circ} \mathrm{C}$; ${ }^{1} \mathrm{H}$ NMR $\left(300 \mathrm{MHz}, \mathrm{CDCl}_{3}\right) \delta 3.91(\mathrm{td}, J 7.5,3.2 \mathrm{~Hz} \mathrm{1H}, \mathrm{HOCH})$, 2.99 (t, J 6.4, $2.8 \mathrm{~Hz}, 2 \mathrm{H}, \mathrm{NCH}_{2}$ ), 2.89 (td, J $5.8 \mathrm{~Hz}, 1 \mathrm{H}$, $\mathrm{NCH}), 2.20-2.23\left(\mathrm{~m}, 2 \mathrm{H}, \mathrm{NCOCH}_{2}\right), 2.10-2.15(\mathrm{~m}, 2 \mathrm{H}$, $\left.\mathrm{COCH}_{2}\right), 1.25\left(\mathrm{~s}, 3 \mathrm{H}, \mathrm{CH}_{3}\right), 1.09$ (s, 3H, $\left.\mathrm{CH}_{3}\right), 0.99$ (s, 3H, $\left.\mathrm{CH}_{3}\right), 0.97$ (s, 3H, $\left.\mathrm{CH}_{3}\right), 0.89\left(\mathrm{~s}, 3 \mathrm{H}, \mathrm{CH}_{3}\right), 0.86(\mathrm{~s}, 3 \mathrm{H}$, $\left.\mathrm{CH}_{3}\right) ;{ }^{13} \mathrm{C}$ NMR $\left(75 \mathrm{MHz}, \mathrm{CDCl}_{3}\right) \delta 172.1,166.5,85.8$, 84.6, 70.6, 69.8, 55.4, 52.2, 50.1, 49.5, 48.2, 47.5, 43.1, $41.7,40.2,39.6,36.5,33.8,33.2,32.6,32.0,30.9,30.0$, 28.6, 28.2, 27.5, 26.4, 25.8, 25.1, 21.2, 20.3, 18.6, 18.2, 17.4, 17.0, 16.3, 15.8; ESI-MS $m / z 601.5[\mathrm{M}+\mathrm{H}]^{+}$.

\section{Antibacterial activity assays}

The antibacterial activity, synergistic antibacterial activity and cytotoxicity tests were carried out using the methods described previously. ${ }^{7,10}$ The minimum inhibitory concentration (MIC) values against several drug-sensitive bacteria (S. aureus RN4220, B. subtilis
168, E. coli DH5 $\alpha$ and P. aeruginosa PAO1) and drugresistant bacteria (methicillin-resistant $S$. aureus (MRSA USA300), vancomycin-resistant $E$. faecium (VRE) and $K$. pneumonia) were determined by the standard Luria-Bertani medium dilution technique. (3-(4,5-Dimethylthiazol-2-yl)2,5-diphenyl tetrazolium bromide (MTT) method was used to detect the cytotoxicity of synthetic compounds on human breast cancer cells (MCF-7), human epithelial kidney (HEK-293) and human normal liver cell (L02), and 5-fluorouracil was used as a positive control.

Propensity to induce bacterial resistance

The most active compound 13d was selected to investigate the developing rate of bacterial resistance according to the literature. ${ }^{14}$ The standard strains of MRSA and $E$. coli were continuously subcultured from MIC. After MRSA and $E$. coli were cultured in fresh medium, the new MIC value was recorded every $24 \mathrm{~h}$. The positive control groups, which were exposed to 2-fold dilutions with the above reference drugs, were performed simultaneously. The experiment was sustained for 16 days.

\section{Bactericidal time-kill kinetics}

The cells of MRSA USA300 (E. coli) were incubated at $37^{\circ} \mathrm{C}$ for $24 \mathrm{~h}(48 \mathrm{~h})$ followed by the adjustment of cells to about $1 \times 10^{6}$ colony forming units $(\mathrm{CFU}) \mathrm{mL}^{-1}$. Bacterial suspensions $(1 \mathrm{~mL})$ were treated with $\mathbf{1 3 d}(1 \mathrm{~mL})$ against MRSA (MIC and 2 MIC) and E. coli (2 MIC and 3 MIC) at different concentrations and then further cultured at $37^{\circ} \mathrm{C}$ with shaking. At $0.5,1,2,3,5,7,9,11$ and $13 \mathrm{~h}$, aliquots $(100 \mu \mathrm{L})$ were removed from the cultures and serially diluted 10-fold with phosphate buffer solution (PBS), and plated onto sterile Mueller-Hinton agar medium. Plates were then further cultured for another $24 \mathrm{~h}$ at $37^{\circ} \mathrm{C}$. After the treatment, the number of colonies growth of bacteria was recorded. The experiments were repeated twice.

\section{Biofilm disruption assay}

MRSA and $E$. coli cultures for $6 \mathrm{~h}$ (medium logarithmic) were suspended to $1 \times 10^{6} \mathrm{CFU} \mathrm{mL}^{-1}$. The plates containing the suspension $(100 \mu \mathrm{L})$ were then incubated under the fixed conditions for a period of time (MRSA: $24 \mathrm{~h}$; E. coli: $48 \mathrm{~h}$ ). After the treatment, the culture medium was removed and the bacteria cells were washed with PBS for single time. Compound 13d (100 $\mu \mathrm{L})$ with different concentrations (4, 8, 16 and $32 \mu \mathrm{g} \mathrm{mL}^{-1}$ ) was added to the wells, which already contained the formed bacterial biofilm, and the incubation was continued for $24 \mathrm{~h}$. The addition of $\mathbf{1 3 d}$ 
was replaced with $100 \mu \mathrm{L}$ medium as control. After this, the culture solution was removed and the unadhered cells were washed and removed with PBS. Next, $100 \mu \mathrm{L}$ of trypsin-ethylenediaminetetraacetic acid (EDTA) mixed solution was added to the above treated bacterial cells for suspension. The cell suspension ability of the biofilm was evaluated by serial 10 -fold dilution method on agar plates. After incubation for $24 \mathrm{~h}$, the number of colonies was carefully counted and the total bacterial $\log _{10} \mathrm{CFU} \mathrm{mL} \mathrm{mL}^{-1}$ was recorded. The results obtained were further compared with the control group.

\section{Cytoplasmic membrane depolarization assay}

MRSA and $E$. coli cultures for $6 \mathrm{~h}$ (medium logarithmic) were collected $(10,000 \mathrm{rpm}, 1 \mathrm{~min})$, washed and then suspended in $100 \mathrm{mM}$ potassium chloride, $5 \mathrm{mM}$ 4-(2-hydroxyethyl)-1-piperazineethanesulfonic acid (HEPES) buffer ( $\mathrm{pH} \mathrm{7.3)} \mathrm{and} 5 \mathrm{mM}$ glucose at a ratio of $1: 1: 1$. Then, $150 \mu \mathrm{L}$ of bacterial suspension were added to the tube containing a membrane potential sensitive dye 3,3-dipropylthiadicarbocyanine iodide $\left(\mathrm{DiSC}_{3} 5\right.$ ) $(8 \mu \mathrm{M}, 50 \mu \mathrm{L})$. The above cell suspension was then preincubated at $37^{\circ} \mathrm{C}$ for $40 \mathrm{~min}$ for MRSA and $80 \mathrm{~min}$ for $E$. coli. The excitation wavelength and emission wavelength for fluorescence were monitored at 622 and $670 \mathrm{~nm}$, respectively. The treated suspension was carefully transferred to another tube containing $10 \mu \mathrm{L}$ of compound 13d (minimum bactericidal concentration, MBC: $8 \mu \mathrm{g} \mathrm{mL}^{-1}$ against MRSA and $12 \mu \mathrm{g} \mathrm{mL} \mathrm{m}^{-1}$ against E. coli) and the fluorescence intensity was detected. The experiment of treating pre-cultured bacteria and dyes with water $(10 \mu \mathrm{L})$ instead of compounds was regarded as a control experiment.

\section{Confocal laser scanning microscopy (CLSM)}

The integrity of the bacterial membrane was determined using the LIVE/DEAD Baclight bacterial activity kit (Thermal Fischer, Waltham, USA). In the logarithmic growth stage, MRSA and E. coli were centrifuged at $5000 \mathrm{rpm}$ for $5 \mathrm{~min}$, and then the centrifuged cells were washed twice with PBS $(10 \mathrm{mM}, \mathrm{pH}=7.2)$. The cells were suspended in PBS and adjusted to $1 \times 10^{6} \mathrm{CFU} \mathrm{mL}^{-1}$ (optical density, $\left.\mathrm{OD}_{600}=0.2-0.4\right)$. After that, compound 13d (MBC: $8 \mu \mathrm{g} \mathrm{mL} \mathrm{m}^{-1}$ against MRSA and $12 \mu \mathrm{g} \mathrm{mL}^{-1}$ against $E$. coli) was mixed with bacterial suspension and cultured at $37^{\circ} \mathrm{C}$ for $7 \mathrm{~h}$. Next, the dyes Syto 9 and propidium iodide (PI) were added to the cell suspension, which were incubated for $20 \mathrm{~min}$ in a dark environment and then observed with a confocal laser scanning microscopy. The experiment treated with PBS instead of compound 13d was used as a control group. These experiments were repeated twice.

Intracellular $\mathrm{K}^{+}$ion leakage assay

The $\mathrm{K}^{+}$efflux from MRSA and E. coli cells was measured using an atomic absorption spectrophotometer (AA320N, Beijing, China). The release of $\mathrm{K}^{+}$were performed according to the method described in the literature. ${ }^{15}$ Briefly, MRSA and E. coli cultures for $6 \mathrm{~h}$ (medium logarithmic) were collected (10,000 rpm, $1 \mathrm{~min}$ ), washed and then suspended in $10 \mathrm{mM}$ HEPES buffer ( $\mathrm{pH} 7.3$ ) and $5 \mathrm{mM}$ glucose at a ratio of 1:1. The concentration of bacteria cells were adjusted to about $10^{7} \mathrm{CFU} \mathrm{mL} \mathrm{m}^{-1}$. After this, one milliliter of these suspensions were then incubated with compound 13d at different concentrations (MIC, $2 \mathrm{MIC}$ ) at $37^{\circ} \mathrm{C}$ for different time. After centrifugation, the amounts of released $\mathrm{K}^{+}$in the supernatants were measured. The experiment treated with PBS instead of compound 13d was used as a control group. These experiments were repeated twice.

\section{Interaction with DNA}

In the process of determining the interaction between drugs and DNA, UV-visible spectrophotometry is one of the most commonly used methods. Calf thymus DNA was purchased from Sigma-Aldrich (Missouri, USA). The concentration of DNA in the stock solution (0.1 M Tris-HCl, $\mathrm{pH}$ 7.2) was detected using ultraviolet absorption spectrophotometry based on Lambert-Beer law (the molar absorbance coefficient of DNA at $260 \mathrm{~nm}$ is $6500 \mathrm{~L} \mathrm{~mol}^{-1} \mathrm{~cm}^{-1}$ ). DNA purity was determined by measuring the ratio of absorbance of the DNA solution at 260 to $280 \mathrm{~nm}$. During the experiment, the ratio was 1.9 , indicating that the purity was up to scratch. DNA solution $\left(2 \mathrm{~mL}, 6.30 \times 10^{-6} \mathrm{M}\right)$ were added to a tube containing various concentrations of compound 13d. The concentrations of $\mathbf{1 3 d}$ were $0-2.09 \times 10^{-6} \mathrm{M}(0-3 \mathrm{MIC})$ at an increment of $0.42 \times 10^{-6}$. Absorption spectra were expressed at $298 \mathrm{~K}$ in the range of $225-340 \mathrm{~nm}$.

\section{Results and Discussion}

\section{Synthetic chemistry}

The synthesis was carried out with 20(S)-protopanaxadiol (PPD), one of the main components of Panax ginseng, as the starting material (Scheme 1). Protection of the 3,12-dihydroxy of PPD as a diacetate in the presence of DMAP and acetic anhydride gave 5. Epoxidation of $\mathbf{5}$ with 
3-chloroperbenzoic acid ( $m$-CPBA) resulted in $\mathbf{6}$, which was further oxidized by Jone's reagent to provide acetylated lactone 7. After alkali treatment and acidification, the lactone 8 with the expected yield was obtained. The 3-hydroxy group of lactone $\mathbf{8}$ was oxidized by pyridinium chlorochromate (PCC) to produce ketone $\mathbf{9}$, which then underwent nucleophilic addition and intramolecular elimination to generate oxime 10. The mixture of $3 \beta$ and $3 \alpha$ amines were obtained by reduction of $\mathbf{1 0}$ with sodium borocyanate in the presence of titanium chloride and ammonium acetate. The mixture was difficult to purify directly, but it could be easily separated by silica gel column chromatography after the tert-butoxycarbonylation. Next, trifluoroacetic acid was used to deprotect the tert-butyloxycarbonyl group to produce $3 \beta$-amine compound 11. ${ }^{16,17} \mathbf{1 1}$ reacted with a series of acids and anhydrides to form the novel derivatives 11a-11i. In addition, as shown in Scheme 1, 11 reacted with a series of Boc-amino acids to give intermediates 12a-12e, and finally target compounds 13a-13e were obtained by deprotection using trifluoroacetic acid.

In vitro antibacterial activity

To evaluate the antibacterial efficacy, the obtained novel ocotillol-type derivatives were challenged against a wide spectrum of drug-sensitive bacteria such as $S$. aureus

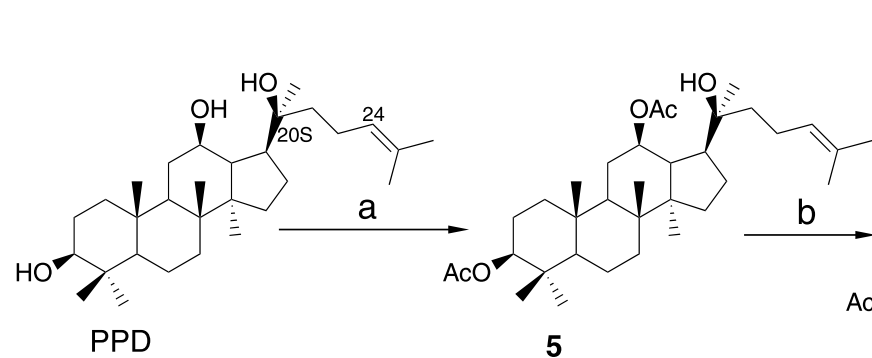

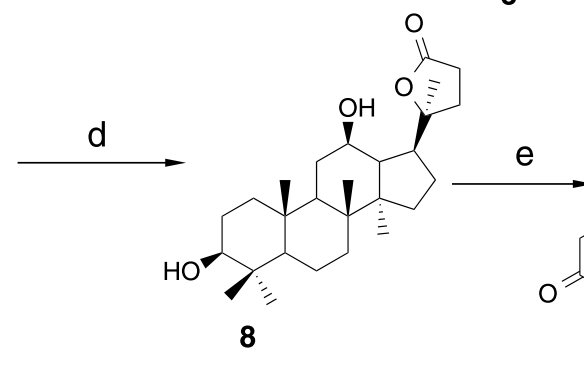

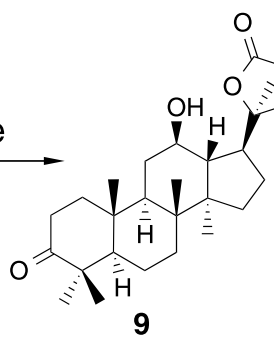

6

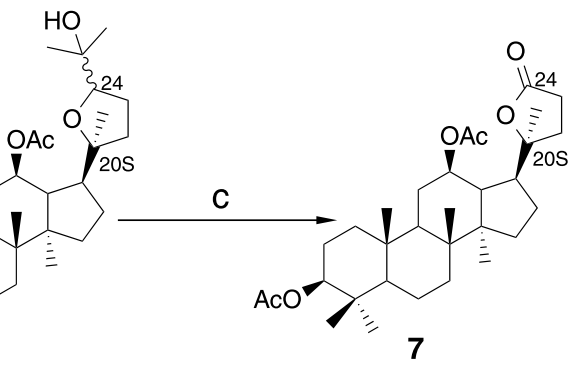

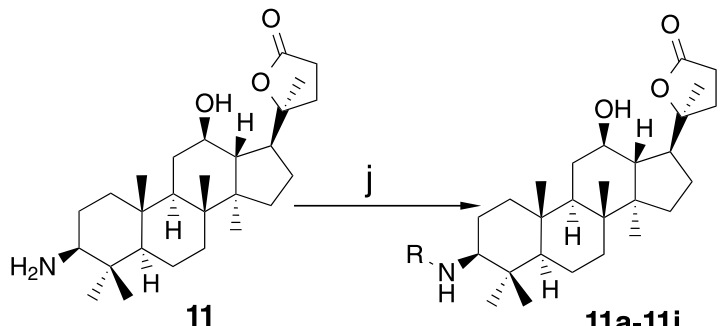

$$
10
$$

10

g, h, i

11b. $R=$<smiles>CC(=O)c1ccccc1</smiles><smiles>CC(=O)c1cncc(I)c1</smiles><smiles></smiles>

11a-11i

$$
\text { I }
$$

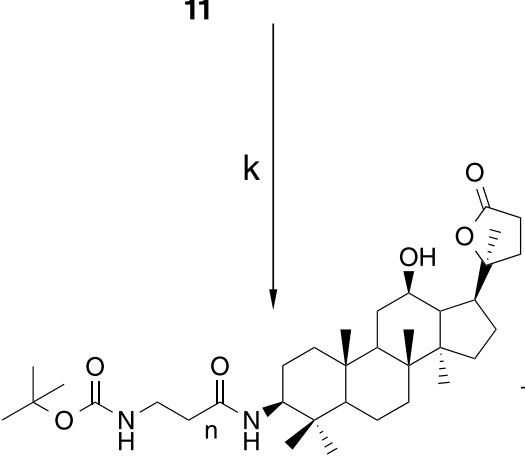

12a-12e<smiles>CC(=O)CCCCC(=O)OC=[18O]</smiles><smiles></smiles><smiles>CC(=O)/C=C/c1ccc(P=[Te])cc1</smiles><smiles>[H][R1]=COC(=O)CCCC(C)=O</smiles>
11i. $R=$<smiles>CC(=O)c1ccccc1C(=O)O</smiles>

Scheme 1. Synthesis of derivatives 11a-11i and 13a-13e. (a) Pyr, $\mathrm{Ac}_{2} \mathrm{O}$, DMAP, rt, 8 h, 75\%; (b) $\mathrm{CH}_{2} \mathrm{Cl}_{2}, m$-CPBA, rt, 12 h, 72\%; (c) Jone's reagent,

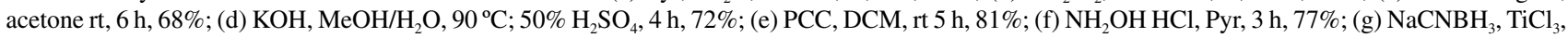
$\mathrm{AcONH}_{4}, \mathrm{MeOH}, 16 \mathrm{~h}$; (h) $\mathrm{Boc}_{2} \mathrm{O}, \mathrm{DCM}$, rt, 6 h, 40\%; (i) TFA, DCM, rt, 4 h, then $\mathrm{NaHCO}_{3}, 76 \%$; (j) EDCI, DMAP, DCM, different acids/anhydride, rt, 6-18 h, 43-77\%; (k) EDCI, DMAP, Boc-amino acids, $\mathrm{CH}_{2} \mathrm{Cl}_{2}$, rt 10-20 h; (l) TFA, DCM, rt, 3-4 h, then $\mathrm{NaHCO}_{3}, 28-45 \%$, from 11-13. 
RN4220, B. subtilis 168, E. coli DH5 $\alpha$, and P. aeruginosa PAO1 and drug-resistant bacteria such as methicillinresistant S. aureus (MRSA USA300), vancomycin-resistant E. faecium (VRE), $\beta$-lactam-resistant $K$. pneumonia (Table 1). In general, compounds 11f, 11g, 11i and 13a-13d displayed good antibacterial activity with MIC values of 1-8 $\mu \mathrm{g} \mathrm{mL}^{-1}$ against $S$. aureus and 2-8 $\mu \mathrm{g} \mathrm{mL}^{-1}$ against $B$. subtilis, respectively. For drug-sensitive bacteria, 3-amino substituted compound 13d was found to be the most active with MICs of 1-2 $\mu \mathrm{g} \mathrm{mL} \mathrm{m}^{-1}$ against Grampositive bacteria and 4-16 $\mu \mathrm{g} \mathrm{mL}^{-1}$ against Gram-negative. Moreover, the inhibitory effects of these compounds were found to be more active toward Gram-positive bacteria than the Gram-negative bacteria. Compared to the parent molecule 11, compounds 11f, $11 \mathrm{~g}$ and $\mathbf{1 1 i}$ with aliphatic or aromatic carboxylic acid groups also showed enhanced activities against Gram-positive bacteria with MICs ranging from 4 to $8 \mu \mathrm{g} \mathrm{mL}^{-1}$. Meanwhile, compound $\mathbf{1 1 h}$ bearing an $\alpha, \beta$-unsaturated carboxylic acid at C-3 displayed only mild activity with MICs of 64-128 $\mu \mathrm{g} \mathrm{mL}^{-1}$, which was inferior to that of the molecule 11. Compared with 11f, $11 \mathrm{~g}$ and 11i, the decreased activity of $\mathbf{1 1 h}$ was probably due to the increased $\mathrm{p} K_{\mathrm{a}}$ caused by $\pi$-electron conjugation. Additionally, compounds 13a-13d, with unprotected primary amino groups at C-3, showed good inhibitory activity against $S$. aureus with MIC values of 1-4 $\mu \mathrm{g} \mathrm{mL} \mathrm{mL}^{-1}$, and against $B$. subtilis with MIC values of 2-8 $\mu \mathrm{g} \mathrm{mL}^{-1}$, respectively. These amino acid derivatives were also effective against Gram-negative bacteria, with MICs of 4-32 $\mu \mathrm{g} \mathrm{mL}^{-1}$ against $E$. coli and 16-128 $\mu \mathrm{g} \mathrm{mL}^{-1}$ against $P$. aeruginosa. However, compound $\mathbf{1 3 e}$, which was also amino acid derivative, displayed only moderate to mild activity with MICs of 32-64 $\mu \mathrm{g} \mathrm{mL}^{-1}$ against both Gram-positive bacteria and Gram-negative bacteria. The structures of 13a-13e are similar in all respects except for the length of C-3 position. Structural comparison of 13a-13e showed that a specific chain length of C-3 can significantly influence the activity of amino acid derivatives, and the length of 2-8 carbon atoms at C-3 is preferred. Meanwhile, compounds 11a-11e, which were amide derivatives, displayed decreased activities against Gram-positive and Gram-negative bacteria, probably due to reduced water solubility. These results suggested that the C-3 substituents significantly affected the activity of the compounds, and the derivatives with amino or carboxyl groups showed the best activity.

Not only active against drug-sensitive bacteria, these ocotillol-type derivatives also displayed good to moderate activity against drug-resistant bacteria such as MRSA and $\beta$-lactam-resistant $K$. pneumonia (Table 1). Like the drugsensitive bacteria, the synthesized compounds revealed similar tendency in their activity against drug-resistant bacteria. Compounds 13a-13d showed good inhibitory effects with MICs of 4-16 $\mu \mathrm{g} \mathrm{mL}^{-1}$ against MRSA, while 11f, 11g and 11i displayed moderate antibacterial activity against this pathogen with MICs of $32 \mu \mathrm{g} \mathrm{mL}^{-1}$, respectively.

Table 1. In vitro antibacterial activity of the synthesized derivatives

\begin{tabular}{|c|c|c|c|c|c|c|c|}
\hline \multirow{3}{*}{ Compound } & \multicolumn{7}{|c|}{$\mathrm{MIC} /\left(\mu \mathrm{g} \mathrm{mL}^{-1}\right)$} \\
\hline & \multicolumn{4}{|c|}{ Drug-sensitive bacteria } & \multicolumn{3}{|c|}{ Drug-resistant bacteria } \\
\hline & S. aureus & B. subtilis & E. coli & P. aeruginosa & MRSA & K. pneumonia & VRE \\
\hline 11 & 16 & 32 & 32 & 128 & 64 & 64 & 128 \\
\hline $11 \mathbf{a}$ & 64 & 64 & 128 & $>128$ & $>128$ & 128 & 128 \\
\hline $11 b$ & 128 & 128 & $>128$ & $>128$ & $>128$ & 128 & $>128$ \\
\hline $11 \mathrm{c}$ & 128 & 128 & 128 & $>128$ & 128 & $>128$ & $>128$ \\
\hline 11d & 64 & 64 & 128 & $>128$ & $>128$ & 128 & $>128$ \\
\hline $11 e$ & 128 & 128 & $>128$ & $>128$ & 64 & $>128$ & $>128$ \\
\hline $11 f$ & 8 & 4 & 64 & 128 & 32 & 64 & 128 \\
\hline $11 \mathrm{~g}$ & 8 & 8 & 64 & 64 & 32 & 64 & 128 \\
\hline $11 \mathrm{~h}$ & 64 & 64 & 64 & 128 & 128 & $>128$ & $>128$ \\
\hline $11 \mathrm{i}$ & 8 & 8 & 128 & $>128$ & 32 & 128 & 64 \\
\hline $13 a$ & 4 & 8 & 32 & 64 & 16 & 64 & 64 \\
\hline $13 b$ & 4 & 4 & 32 & 128 & 8 & 64 & 128 \\
\hline $13 c$ & 2 & 4 & 16 & 32 & 8 & 32 & 64 \\
\hline $13 d$ & 1 & 2 & 4 & 16 & 4 & 32 & 64 \\
\hline $13 e$ & 32 & 32 & 64 & 64 & 128 & 64 & 128 \\
\hline KAN & 1 & 0.25 & 1 & 4 & 1 & 4 & 8 \\
\hline
\end{tabular}

MIC: minimum inhibitory concentration; MRSA: methicillin-resistant $S$. aureus; VRE: vancomycin-resistant E. faecium; KAN: kanamycin. 
For $\beta$-lactam-resistant $K$. pneumonia, compounds 13c-13d displayed moderate activity with MIC values of $32 \mu \mathrm{g} \mathrm{mL} \mathrm{m}^{-1}$. Other derivatives could only exhibit mild activity with MIC values of $64-128 \mu \mathrm{g} \mathrm{mL}^{-1}$ against $K$. pneumonia.

\section{Propensity to develop bacterial resistance}

The development of bacterial resistance to most antibiotics is one of the key problems of current times. Therefore, it will be critical to assess the potential occurrence of bacterial resistance to this type of compounds. Compound 13d, which showed the strongest antibacterial activity, was then selected to evaluate the propensity for development of bacterial resistance against both Gram-positive MRSA and Gram-negative E. coli. Norfloxacin and colistin were used as the positive controls (Figure 2). These antimicrobial agents were repeatedly challenged by bacteria, causing bacteria to develop resistance. Interestingly, no greater than a 3-fold increase in the MIC values was observed for 13d against both MRSA and E. coli even after 16 passages, while the MICs of norfloxacin and colistin increased by 18 and 16 times, respectively. These results indicated that compared with some clinical antibiotics such as norfloxacin and colistin, Gram-positive bacteria MRSA and Gram-negative bacteria E. coli are more difficult to develop resistance to this kind of compounds.

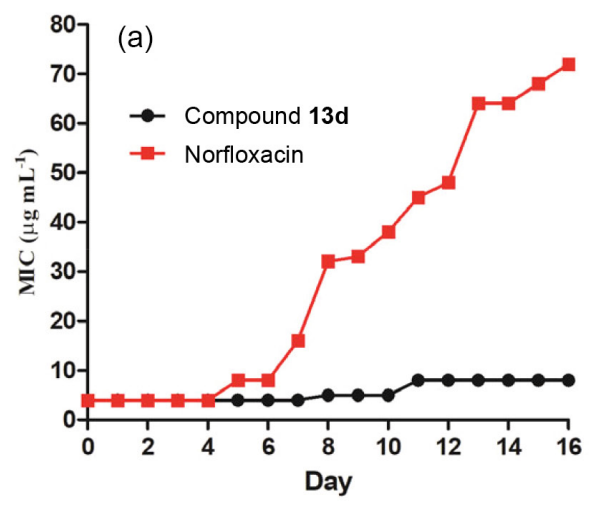

\section{Bactericidal time-kill kinetics}

In order to study the bactericidal activity of the compound with excellent antibacterial activity, the bactericidal effects of compound 13d toward MRSA were studied at two different concentrations (MIC and 2 MIC) using norfloxacin as a positive control (Figure 3). Compound 13d displayed rapid bactericidal activity against this pathogen at $2 \mathrm{MIC}$ (>5 $\log _{10} \mathrm{CFU} \mathrm{mL} \mathrm{mL}^{-1}$ reduction) after $3 \mathrm{~h}$, whereas it showed bacteriostatic effect at MIC. Norfloxacin, for example, showed concentration-dependent activity between $1 \mathrm{MIC}$ and $2 \mathrm{MIC}$, but its effect is antibacterial rather than bactericidal. For $E$. coli, compound 13d showed significant bactericidal activity after $7 \mathrm{~h}$ at $3 \mathrm{MIC}$, while only showed antibacterial activity at the concentration of 2 MIC. The positive group (colistin) exhibited faster bactericidal activity at a concentration of 2 MIC and the bacteria viability decreased to zero at the fifth hour. These results clearly suggested that ocotillol-type compounds exert obviously superiority over the traditionally used antibacterial agents such as norfloxacin and colistin.

\section{Assays of synergistic antibacterial activity}

It has been proved that triterpenoids in natural products exhibit antibacterial activity by increasing the permeability

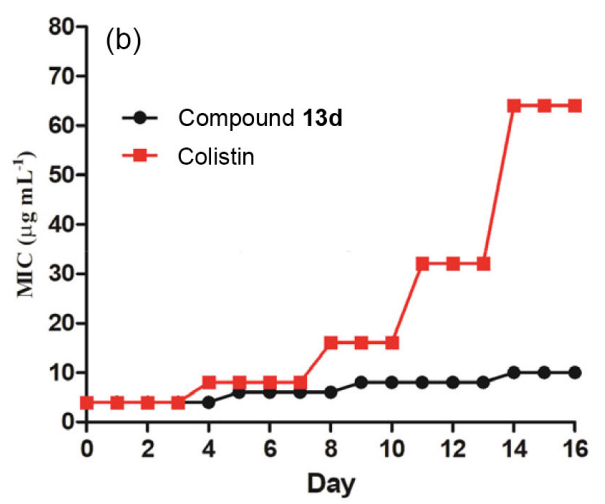

Figure 2. Propensity to induce bacterial resistance of compound 13d against (a) MRSA; (b) E. coli DH5 $\alpha$.
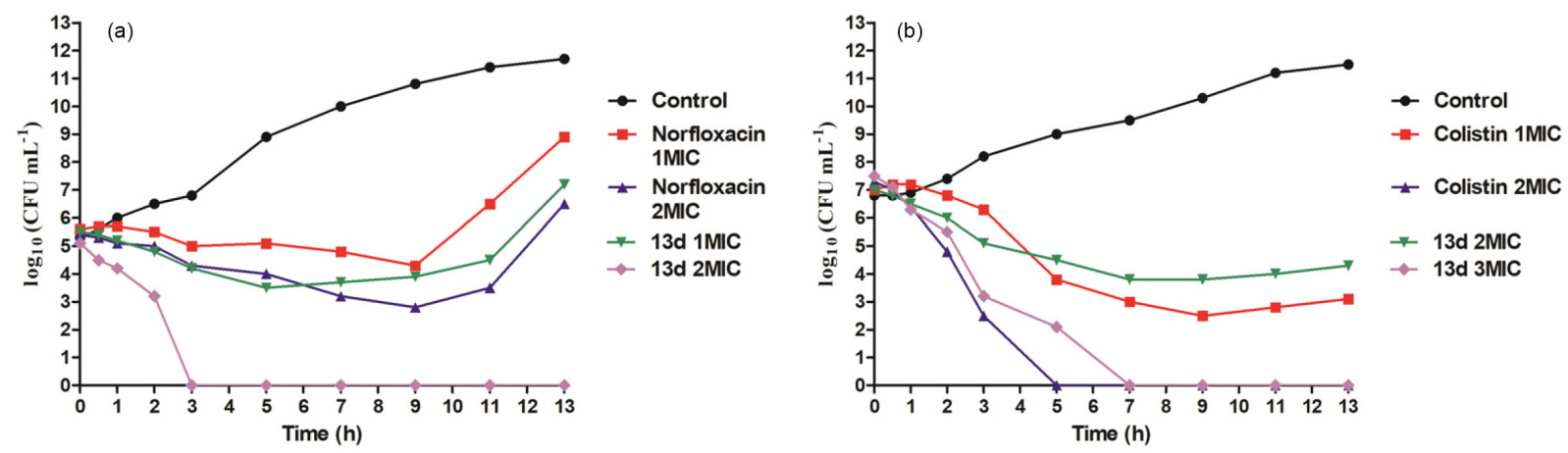

Figure 3. Time-kill kinetics of 13d against (a) MRSA; (b) E. coli DH5 . 
of cell membranes. As membrane perturbs, these compounds may synergistically enhance the antibacterial activity of some clinical antibiotics. Therefore, the synergistic antibacterial activity of compound $\mathbf{1 3 d}$ with kanamycin and chloramphenicol were further tested against MRSA and $E$. coli. Kanamycin and chloramphenicol are commonly used antibiotics, both of which play a role by inhibiting protein synthesis. The fractional inhibition concentration index (FICI) was calculated by fractional inhibition concentration to evaluate the synergistic effects. ${ }^{18}$ As shown in Table 2, the MIC of kanamycin against MRSA was significantly reduced from 1 to $0.25 \mu \mathrm{g} \mathrm{mL} \mathrm{m}^{-1}$ (FICI $=0.31$ ). Strong synergistic inhibition against $E$. coli was also observed when 13d was used in combination with chloramphenicol. The FICI of 13d and chloramphenicol was 0.08 , which was significantly smaller than 0.5 , indicating that they acted synergistically to inhibit the growth of this Gram-negative bacteria. However, only an additive effect was observed when a combination of $\mathbf{1 3 d}$ with kanamycin against $E$. coli $($ FICI $=0.58)$, while others' combinational activities were displayed as indifferent interactions $(1<\mathrm{FICI}<2)$. In contrast, when $\mathbf{1 3 d}$ was combined with kanamycin, the
MBC value of kanamycin against MRSA was significantly reduced from 4 to $2 \mu \mathrm{g} \mathrm{mL}^{-1}$. Surprisingly, chloramphenicol alone was a bacteriostatic agent, but displayed dramatically bactericidal effects against $E$. coli when combined with $\mathbf{1 3 d}$ with $\mathrm{MBC}$ value of $0.25 \mu \mathrm{g} \mathrm{mL} L^{-1}$.

\section{Assay of cytotoxicity}

The selectivity of clinical antibiotics between mammalian cells and bacterial cells has always been a public concern. The cytotoxic tests of compounds 11f-11i and 13a-13d were evaluated against one human cancer cell lines (MCF-7) and two human normal cell line (HEK-293 and L02) using the MTT assay. The results in Table 3 showed that all the tested compounds exhibited good to moderate activity against the cancer cells (half-maximal inhibitory concentration $\left(\mathrm{IC}_{50}\right)$ ca. 8.29-15.36 $\left.\mu \mathrm{g} \mathrm{mL}^{-1}\right)$. Although the activity was not comparable to that of 5-fluorouracil (5-FU, $\mathrm{IC}_{50}$ ca. $0.90 \mu \mathrm{g} \mathrm{mL}^{-1}$ ), the results obtained here pointed out the direction for the study of antitumor activity of this type of compounds. For the normal cells HEK-293 and L02, all the target compounds

Table 2. Synergistic effect of antibiotics with 13d against MRSA USA300 and E. coli DH5 $\alpha$

\begin{tabular}{|c|c|c|c|c|c|c|}
\hline \multirow{2}{*}{ Compound } & \multicolumn{2}{|c|}{$\mathrm{MIC} /\left(\mu \mathrm{g} \mathrm{mL}^{-1}\right)$} & \multicolumn{2}{|c|}{$\mathrm{MBC} /\left(\mu \mathrm{g} \mathrm{mL}^{-1}\right)$} & \multicolumn{2}{|c|}{ FICI (FIC index $)^{\mathrm{a}}$} \\
\hline & MRSA USA300 & E. coli DH5 $\alpha$ & MRSA USA300 & E. coli $\mathrm{DH} 5 \alpha$ & MRSA USA300 & E. coli $\mathrm{DH} 5 \alpha$ \\
\hline KAN & 1 & 1 & 4 & 2 & - & - \\
\hline CHL & 4 & 2 & N/A & N/A & - & - \\
\hline $13 d+K A N$ & 0.25 & 0.50 & 2 & 2 & 0.31 & 0.58 \\
\hline $13 d+C H L$ & 4 & 0.12 & N/A & 0.25 & 2.0 & 0.08 \\
\hline
\end{tabular}

aFICI: according to the literature: FIC of drug A (FIC A) = MIC of drug A in combination/MIC of drug A alone; FIC of drug B (FIC B) = MIC of drug B in combination/MIC of drug B alone; hence FICI = FIC A + FIC B. "Synergy" was defined when FICI was less than or equal to 0.5; while "additive" in which the FICI was greater than 0.5 and less than or equal to 1.0; whereas "indifferent" when the FICI was greater than 1.0 and less than or equal to 2.0; and "antagonistic" in cases which the FICI was greater than 2.0; KAN: kanamycin; CHL: chloramphenicol; N/A: not applicable; MRSA: methicillinresistant $S$. aureus.

Table 3. Cytotoxic activity of 11f-11i and 13a-13d against MCF-7, HEK-293 and L02 cells

\begin{tabular}{lccc}
\hline \multirow{2}{*}{ Compound } & \multicolumn{3}{c}{$\left.\mathrm{IC}_{50}^{\mathrm{a}, \mathrm{b}} /(\mu \mathrm{g} \mathrm{mL})^{-1}\right)$} \\
\cline { 2 - 4 } & MCF-7 (breast cancer) & HEK-293 $($ human epithelial kidney cell) & L02 (human normal liver cell) \\
\hline $\mathbf{1 1 f}$ & $8.29 \pm 1.68$ & $85.22 \pm 3.16$ & $98.35 \pm 4.25$ \\
$\mathbf{1 1 g}$ & $9.81 \pm 2.04$ & $88.45 \pm 2.89$ & $95.21 \pm 3.04$ \\
$\mathbf{1 1 h}$ & $12.31 \pm 2.37$ & $86.32 \pm 3.30$ & $102.24 \pm 7.78$ \\
$\mathbf{1 1 i}$ & $15.36 \pm 1.15$ & $88.15 \pm 2.99$ & $98.67 \pm 4.02$ \\
$\mathbf{1 3 a}$ & $10.21 \pm 1.92$ & $78.56 \pm 2.15$ & $95.11 \pm 3.75$ \\
13b & $9.55 \pm 2.69$ & $75.26 \pm 2.66$ & $89.24 \pm 2.88$ \\
13c & $14.67 \pm 3.11$ & $90.33 \pm 3.01$ & $104.67 \pm 3.98$ \\
13d & $13.52 \pm 2.90$ & $92.54 \pm 2.94$ & $101.26 \pm 4.39$ \\
5-FU & $0.91 \pm 0.25$ & - & -
\end{tabular}

${ }^{\mathrm{a}} \mathrm{C}_{50}$ is the concentrations required to inhibit $50 \%$ of cell growth; ${ }^{\mathrm{b}}$ results are expressed as the mean \pm standard deviation of three independent experiments; 5-FU: 5-fluorouracil. Effect of compound 13d on bacterial biofilm. 
displayed much higher $\mathrm{IC}_{50}$ values against HEK-293 (ca. $90 \mu \mathrm{g} \mathrm{mL}^{-1}$ ) and L02 (ca. $100 \mu \mathrm{gL}^{-1}$ ) cells than that of the positive control 5-FU, and thus they will not affect cell viability at their antibacterial MICs. These results suggested that compounds 11f-11i and 13a-13d could show in vitro antibacterial effects at non-cytotoxic concentrations.

\section{Biofilm disruption assay}

The formation of biofilm is a means of self-protection of bacteria, which often leads to decreasing the therapeutic effects and increasing the drug resistance. More importantly, biofilm accounts for more than $70 \%$ of human bacterial infection, which causes a series of obstacles to antibacterial treatment. ${ }^{19}$ Therefore, it is important to evaluate the efficiency of this type of compounds to eradicate the established biofilms of Gram-positive and Gram-negative bacteria. The most active compound 13d was selected to test the ability to disperse performed MRSA and E. coli biofilms according to the literature ${ }^{14}$ (Figure 4). Mature MRSA biofilms (cultured for $24 \mathrm{~h}$ ) were treated at four different concentrations of $\mathbf{1 3 d}(4,8,16$ and $32 \mu \mathrm{g} \mathrm{mL}-1)$ with an initial count of $11.6 \log _{10} \mathrm{CFU} \mathrm{mL} \mathrm{mL}^{-1}$ of bacteria. After treatment, the cell viability in the biofilms decreased to $10.21,8.50$ and $5.26 \log _{10} \mathrm{CFU} \mathrm{mL} \mathrm{mL}^{-1}$, corresponding to 4,8 and $16 \mu \mathrm{g} \mathrm{mL}{ }^{-1}$, respectively. Furthermore, the highest concentration of 13d $\left(32 \mu \mathrm{g} \mathrm{mL} \mathrm{mL}^{-1}\right)$ displayed zero cell viability in MRSA biofilms indicating that the established biofilms disappeared completely. In contrast, mature E. coli biofilms (cultured for $48 \mathrm{~h}$ ) were also similarly treated with an initial count of $23.55 \log _{10} \mathrm{CFU} \mathrm{mL} \mathrm{L}^{-1}$ of bacteria at $4,8,16$ and $32 \mu \mathrm{g} \mathrm{mL} L^{-1}$, respectively. The results in Figure 4 showed that the cell viability in biofilms at 4,8 , 16 and $32 \mu \mathrm{g} \mathrm{mL}^{-1}$ decreased to $22.01,20.50,15.62$ and $10.38 \log _{10} \mathrm{CFU} \mathrm{mL}-1$, respectively, while cell viability

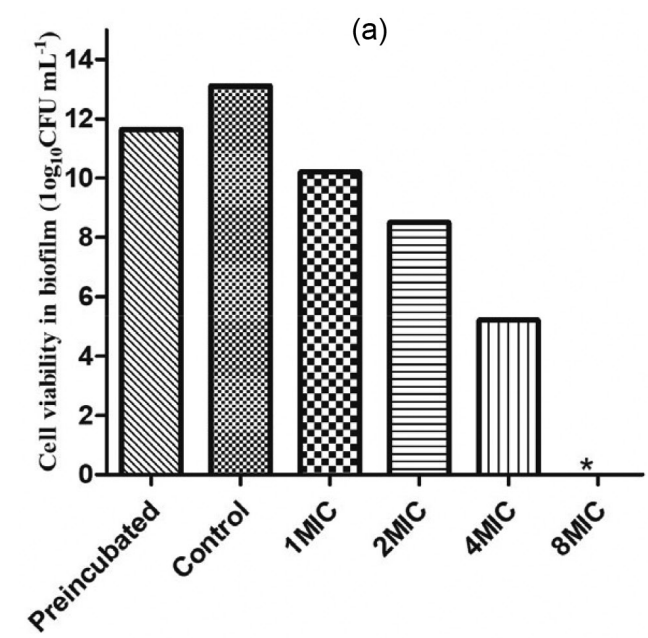

in control group increased to $24.62 \log _{10} \mathrm{CFU} \mathrm{mL} \mathrm{mL}^{-1}$ in the untreated biofilm group. These results obtained here suggested that ocotillol-type derivatives exert the ability to disperse established biofilms and thus would be a class of ideal compounds to tackle infections caused by MRSA and E. coli.

Analysis of the relation between lipid-water partition coefficient and antibacterial activity

Lipid-water partition coefficient is one of the important properties of drugs. Appropriate lipid-water partition coefficient is beneficial to better absorption of drugs. Therefore, it is important to acquire a good understanding of the related physical and chemical properties such as lipophilicity and hydrophilicity. Partition coefficient is often used to determine the lipophilicity and hydrophilicity of a drug. As a result, the theoretical calculated values for $\log \mathrm{P}(\mathrm{C} \log \mathrm{P})$ were obtained in the present study by using Commercial ChemBioOffice 2010. ${ }^{20}$ As shown in Table 4, the compounds with low lipophilicity $(\mathrm{ClogP} \leq 4.03)(\mathbf{1 1 f}$, 13a-13e) exhibited good to moderate antibacterial activity against $S$. aureus, B. subtilis, E. coli and MRSA, which indicated that the introduction of hydrophilic groups like carboxy group and amino group into the steroid skeleton was detrimental to their antibacterial action. In the case of high lipophilicity, the synthesized derivatives with high $\mathrm{C} \log \mathrm{P}$ values $(\mathrm{C} \log \mathrm{P} \geq 4.15)$ displayed mild to poor potency against all the tested pathogens. These highly lipophilic substituents might result in significant decrease in antibacterial activity. However, although $\mathbf{1 1 g}$ and 11i (3-substituted carboxylic acid derivatives) displayed high ClogP values $(4.30,5.81)$ compared to parent molecule $\mathbf{1 1}$ (4.15), the two compounds surprisingly showed good antibacterial activity with MIC values of $8 \mu \mathrm{g} \mathrm{mL} \mathrm{m}^{-1}$ against

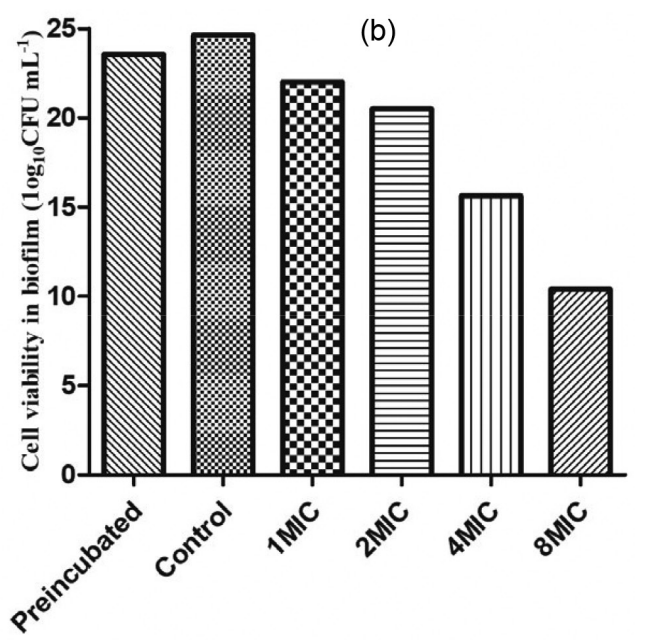

Figure 4. Biofilm disperse by 13d: (a) cell viability in biofilms of MRSA and (b) E. coli, obtained by plating and counting the viable bacteria after treating. 
S. aureus and B. subtilis, respectively. These results suggest that substitutions at C-3 side chain of the steroid skeleton are critical determinants of antibacterial activity against Gram-positive and Gram-negative bacteria, specially the water-soluble groups like amino and carboxyl groups, which may be more conducive to the improvement of activity.

Table 4. ClogP values of compounds 11, 11a-11i and 13a-13e

\begin{tabular}{lc}
\hline Compound & ClogP \\
\hline 11 & 4.15 \\
11a & 4.36 \\
11b & 6.26 \\
11c & 6.60 \\
11d & 4.92 \\
11e & 4.87 \\
11f & 4.03 \\
11g & 4.30 \\
11h & 4.44 \\
11i & 5.81 \\
13a & 3.28 \\
13b & 3.35 \\
13c & 3.60 \\
13d & 3.71 \\
13e & 3.98 \\
\hline
\end{tabular}

Structure-activity relationships (SARs) of ocotillol-type derivatives

Based on the antibacterial activity of the synthesized derivatives, a plausible structure-activity relationships (SARs) could also be summarized (Figure 5). Hydrogen bond donors at $\mathrm{C}-3$ are required for maintaining or improving activity against Gram-positive and Gram-negative bacteria, whereas decreased activity was observed when the amino group at C-3 position converted to amides. However, when the amino groups at $\mathrm{C}-3$ were replaced by acidic amides, the antimicrobial activity was significantly enhanced. For 3-amino substituted derivatives 13a-13e, compounds 13a-13d showed good antibacterial activity against both Gram-positive and Gram-negative bacteria (S. aureus: $1-4 \mu \mathrm{g} \mathrm{mL}^{-1}$; B. subtilis: $2-8 \mu \mathrm{g} \mathrm{mL}^{-1}$; E. coli: 4-32 $\mu \mathrm{g} \mathrm{mL}^{-1}$ ). However, compound 13e, which was also an amino acid derivative, displayed only mild activity with MICs of 32-64 $\mu \mathrm{g} \mathrm{mL}^{-1}$ against drug sensitive bacteria, which was inferior to that of the parent molecule 11. A comparative study of 13a-13e suggested that a specific chain length of C-3 can significantly influence the antibacterial activity, and the length of 2-8 carbon atoms at C-3 is preferred.

\section{Effect on membrane permeabilization}

Cell membrane has always been one of the important targets in the study of drug mechanism, especially in the field of antibacterial and antitumor agents. Furthermore, triterpenoids from plants are likely to increase the permeability of cell membrane by changing the fluidity of membrane. To confirm that ocotillol-type triterpenoid derivatives acted by damaging the integrity of bacterial cell membrane, the study of mechanism of action was conducted against Gram-positive MRSA and Gram-negative bacteria $E$. coli with the most active compound 13d by spectrophotometry. To determine whether this type of compounds functioned by depolarizing the bacterial membrane, a membrane potential sensitive dye called 3,3-dipropylthiadicarbocyanine iodide ( $\left.\operatorname{DiSC}_{3} 5\right)$ was used. Generally speaking, due to the presence of potential gradient, the dye was absorbed by bacteria and accumulated in the cell membrane, resulting in the decrease of fluorescence intensity. However, when the integrity of the cell membrane is damaged, the dye would be transferred into the solution, resulting in increased fluorescence intensity. Notably, the results in Figure 6 showed that

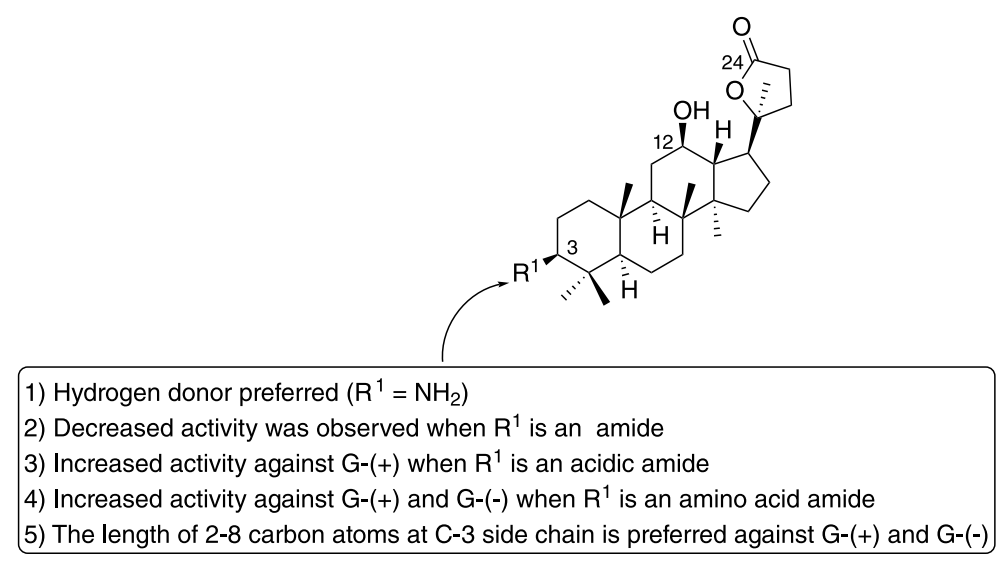

Figure 5. Structure-activity relationship of ocotillol-type derivatives. 

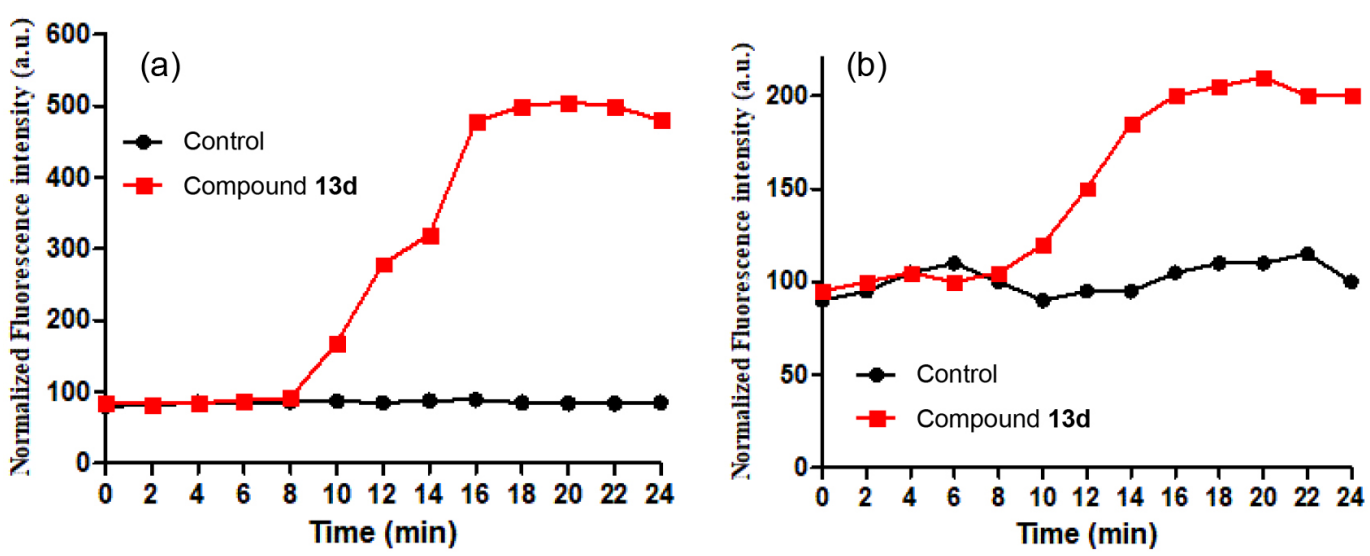

Figure 6. Membrane depolarization against: (a) MRSA ( $\left.8 \mu \mathrm{gL}^{-1}\right)$; and (b) E. coli $\left(12 \mu \mathrm{g} \mathrm{mL}^{-1}\right)$.

the fluorescence intensity of $\mathrm{DiSC}_{3} 5$ was significantly enhanced against both MRSA and E. coli after treated with 13d. These results demonstrated that these ocotilloltype compounds could dissipate the membrane potential of both types of bacteria, thus disrupting the integrity of cell membranes.

Live/dead cell staining assay was also carried out to detected cell viability. Syto-9 can penetrate all cell membranes and label nucleic acids with green fluorescence. PI, on the other hand, is impermeable and can only stain the nucleic acid of damaged bacterial cell membrane with red fluorescence. Therefore, the bacteria with intact membrane showed green fluorescence and were considered to be alive, while the bacteria with damaged membrane showed red fluorescence. As shown in Figure 7, the cells were alive in the control group that was not treated with 13d. Although there were small green areas in the experimental groups, the cells were generally red, which suggested that compound 13d could damage the cell membrane of both Gram-positive and Gram-negative bacteria.

\section{$\mathrm{K}^{+}$efflux induced $\mathbf{1 3 d}$}

In order to study the effects of $\mathbf{1 3 d}$ on cell membrane, the permeability of cell membrane to $\mathrm{K}^{+}$was further discussed. The $\mathrm{K}^{+}$efflux from MRSA and E. coli cells was measured using an atomic absorption spectrophotometer (AA320N, Beijing, China). The release of $\mathrm{K}^{+}$were performed according to the method described in the literature. ${ }^{15}$ The results in Figure 8 exhibited the concentration of $\mathrm{K}^{+}$efflux from MRSA and E. coli which were incubated with 13d for different time. After incubation, the efflux of $\mathrm{K}^{+}$increased significantly in the experimental groups, while the release of $\mathrm{K}^{+}$efflux remained almost unchanged in the control groups. The time course related to $\mathrm{K}^{+}$efflux showed that the permeability

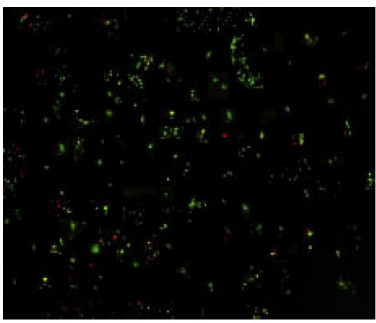

(a)

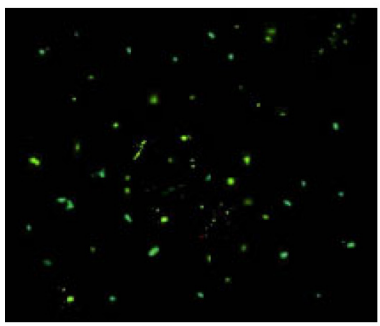

(c)

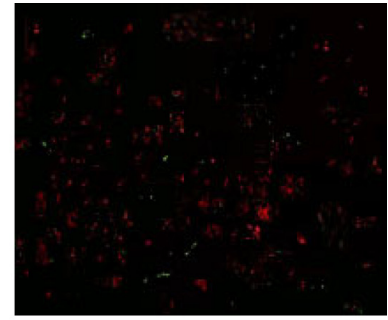

(b)

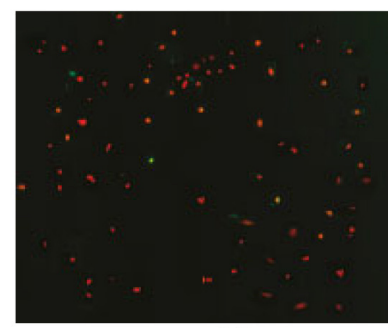

(d)
Figure 7. Fluorescence microscopy of $\mathbf{1 3 d}$ induced permeabilization of MRSA and E. coli by Syto 9 and PI staining. The MRSA cells were treated with PBS (a) control group and 13d (b) $8 \mu \mathrm{g} \mathrm{mL}^{-1}$. The $E$. coli cells were treated with PBS (c), control group and 13d (d) $12 \mu \mathrm{g} \mathrm{mL}^{-1}$.

of cell membrane was concentration dependent. The $\mathrm{K}^{+}$ content increased steadily in the first $4 \mathrm{~h}$, and after this, its value remained constant. These results suggested that this type of triterpenoid derivatives may act on the plasma membrane by increasing permeabilization.

Interaction with DNA

The hyperchromism and hypochromism were important features of double helix DNA structure changes. Hyperchromism is caused by the breakdown of the second component of the DNA double strand and hypochromism results from the stabilization of the DNA through intercalative or electrostatic binding modes of small molecules. ${ }^{21}$ Therefore, the binding of the most active compound 13d to calf thymus DNA was studied at the molecular level. ${ }^{22}$ In the present work, the 

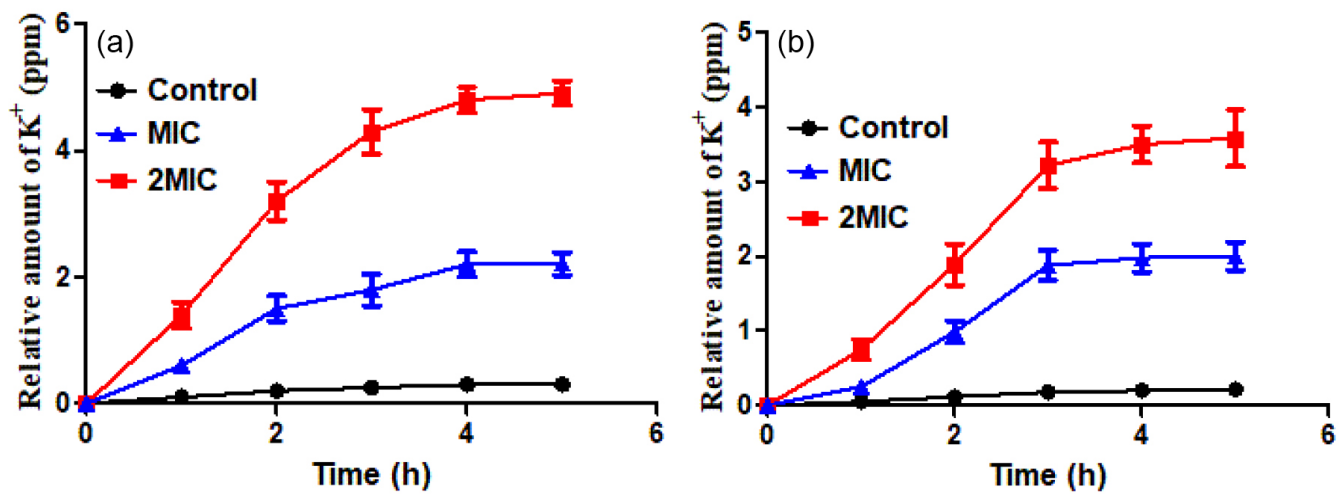

Figure 8. Effects of 13d on the amount of $\mathrm{K}^{+}$released from: (a) MRSA; and (b) E. coli.
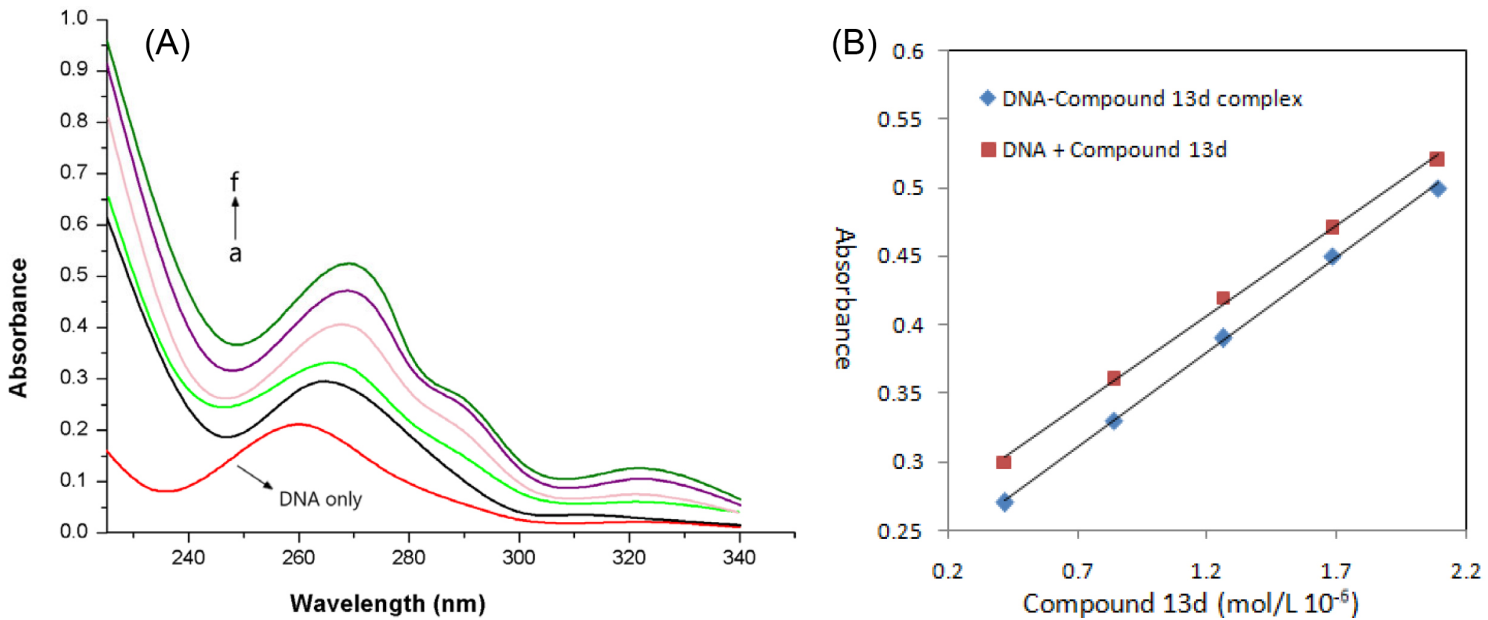

Figure 9. (A) UV spectra of DNA with various concentrations of 13d $\left(0-3 \mathrm{MIC} ; 0-2.09 \times 10^{-6} \mathrm{M}\right.$ for curves a-f at increment of $\left.0.42 \times 10^{-6}\right)$; (B) the absorption of complex of DNA-13d and sum values of free 13d and free DNA at $260 \mathrm{~nm}$; DNA is $6.30 \times 10^{-6} \mathrm{M} ; \mathrm{pH}=7.2, \mathrm{~T}=298 \mathrm{~K}$.

concentration of calf thymus DNA was fixed, and the UV absorption spectrum were obtained by increasing the concentration of 13d. As shown in Figure 9A, the maximum absorption peak of DNA exhibited a red shift with increasing concentrations of 13d. Furthermore, the total absorption values of 13d and free DNA in Figure 9B were larger than that of the DNA-13d complex values. These results suggested the existence of hypochromism in the complex of DNA and 13d. According to long's theory, ${ }^{23}$ hypochromism and red shift are the markers of intercalation between small molecules and DNA duplex. The appearance of hypochromism in the present work indicated the active compound 13d could directly form a complex with double-helical of calf thymus DNA, which may lead to the block of DNA replication.

\section{Conclusions}

In this work, starting from PPD, a series of 3-amino substituted ocotillol-type derivatives were designed and synthesized for the first time. The in vitro antibacterial activity tests showed that some of the new compounds exhibited excellent antibacterial activity. Compound 13d, which was the most active one, displayed particularly strong antibacterial activity against $S$. aureus, B. subtilis, MRSA and E. coli with MIC values of 1-4 $\mu \mathrm{g} \mathrm{mL}^{-1}$, a broad antibacterial spectrum and low cytotoxicity to human normal cells HEK-293 and L02. The following synergistic antibacterial results revealed that ocotillol-type compounds improved the susceptibility of MRSA USA300 and E. coli $\mathrm{DH} 5 \alpha$ to kanamycin and chloramphenicol. Further research suggested that this type of compounds could disperse the established bacterial biofilms, thus delaying the development of drug resistance. Mechanism studies have shown that compound $\mathbf{1 3 d}$ could damage the integrity of cell membranes, which in turn facilitated the antibacterial agents binding to DNA, leading to cell death. Therefore, the membrane active ocotillol-type derivatives of the present investigation could be used as therapeutic agents for the infection caused by the relevant sensitive bacteria and drug-resistant bacteria. These results indicated that ocotillol-type compounds are a promising class of antibacterial agents to fight against super bacteria and deserve further attention. 


\section{Supplementary Information}

Supplementary information $\left({ }^{1} \mathrm{H}\right.$ NMR, ${ }^{13} \mathrm{C}$ NMR and HRMS spectra for some important compounds) is available free of charge at http://jbcs.sbq.org.br as PDF file.

\section{Acknowledgments}

This work was supported by Health commission of Hubei Province scientific research project (grant number WJ2019H534) and Medical and health research project of Yichang (A20-2-056).

\section{References}

1. Arzese, A.; Skerlavaj, B.; Tomasinsig, L.; Gennaro, R.; Zanetti, M.; J. Antimicrob. Chemother. 2003, 52, 375.

2. Schulze, A.; Mitterer, F.; Pombo, J. P.; Schild, S.; Microb. Cell 2021, $8,28$.

3. Davies, D.; Nat. Rev. Drug Discovery 2003, 2, 114.

4. Bi, Y.; Yang, X.; Zhang, T. T.; Liu, Z. Y.; Zhang, X. C.; Lu, J.; Cheng, K. G.; Xu, J. Y.; Wang, H. B.; Lv, G. Y.; Lewis, P. J.; Meng, Q. G.; Eur. J. Med. Chem. 2015, 101, 71.

5. Wang, H. B.; Yu, P. F.; Bai, J.; Zhao, J. Q.; Kong, L.; Zhang, F. X.; Du, G. Y.; Pei, S. Q.; Tian, J. W.; J. Evidence-Based Complementary Altern. Med. 2013, 468.

6. Zhang, J. Q.; Qian, Y. R.; Xu, H. X.; Li, F. L.; Planta Med. 2018, 12, 10 .

7. Zhou, Z. W.; Ma, C.; Zhang, H. Y.; Bi, Y.; Chen, X.; Meng, Q. G.; Xu, J. Y.; Eur. J. Med. Chem. 2013, 68, 444.

8. Bi, Y.; Liu, X. X.; Zhang, H. Y.; Yang, X.; Liu, Z. Y.; Lu, J.; Meng, Q. G.; Molecules 2017, 22, 590.
9. Bi, Y.; Ma, C.; Zhang, H. Y.; Zhou, Z. W.; Yang, J.; Zhang, Z. L.; Meng, Q. G.; Xu, J. Y.; Chem. Biol. Drug Des. 2014, 84, 489.

10. Zhang, Z. Y.; Chen, Z. G.; Zhang, S. Y.; Shao, X.; Zhou, Z. W.; Fitoterapia 2020, 144, 14.

11. Hoque, J.; Konai, M. M.; Sequeira, S. S.; Samaddar, S.; J. Med. Chem. 2016, 59, 10750.

12. Ding, B.; Guan, Q.; Walsh, J. P.; Boswell, J. S.; Winter, T. W.; Winter, E. S.; Boyd, S. S.; Li, C.; Savage, P. B.; J. Med. Chem. 2002, 45, 663 .

13. Du, G. J.; Dai, Q.; Williams, S.; Wang, C. Z.; Yuan, C. S.; AntiCancer Drugs 2011, 22, 35.

14. Hoque, J.; Konai, M. M.; Gonuguntla, S.; Manjunath, G. B.; Yarlagadda, V.; J. Med. Chem. 2015, 58, 5486.

15. Hao, G.; Shi, Y. H.; Tang, Y. L.; Le, G. W.; Peptides 2009, 30 , 1421.

16. Tsukahara, M.; Nishino, T.; Furuhashi, I.; Inoue, H.; Sato, T.; Matsumoto, H.; Chem. Pharm. Bull. 2005, 53, 1103.

17. Ma, C. M.; Cai, S. Q.; Cui, J. R.; Wang, R. Q.; Tu, P. F.; Eur. J. Med. Chem. 2005, 40, 582.

18. Chan, B. C. L.; Ip, M.; Gong, H.; Lui, S. L.; See, R. H.; Phytomedicine 2013, 20, 611.

19. Römling, U.; Balsalobre, C.; J. Intern. Med. 2012, 272, 541.

20. ChemBioOffice; CambridgeSoft, Cambridge, USA, 2010.

21. Kalaivani, P.; Prabhakaran, R.; Dallemer, F.; Poornima, P.; Vaishnavi, E.; Ramachandran, E.; Vijaya Padma, V.; Renganathan, R.; Metallomics 2012, 4, 101.

22. Cui, S. F.; Addla, D.; Zhou, C. H.; J. Med. Chem. 2016, 10, 4488.

23. Long, E. C.; Barton, J. K.; Anal. Chem. Res. 1990, 23, 273.

Submitted: June 1, 2021 Published online: July 16, 2021 